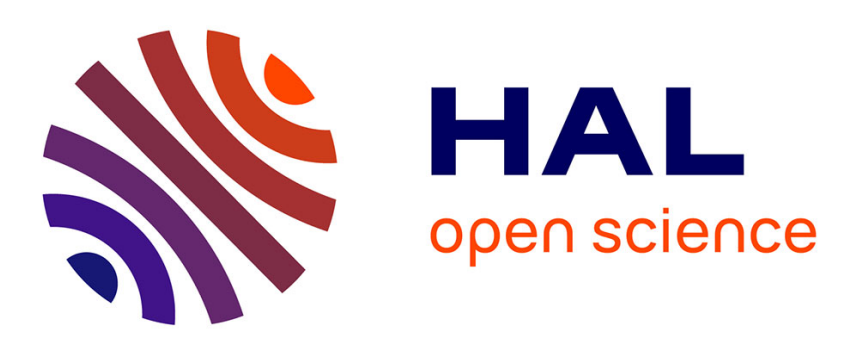

\title{
Thermal, hydric and mechanical behaviours of adobes stabilized with cement
}

Kalifala Dao, Moussa Ouedraogo, Younoussa Millogo, Jean-Emmanuel

Aubert, Moussa Gomina

\section{To cite this version:}

Kalifala Dao, Moussa Ouedraogo, Younoussa Millogo, Jean-Emmanuel Aubert, Moussa Gomina. Thermal, hydric and mechanical behaviours of adobes stabilized with cement. Construction and Building Materials, 2018, 158, pp.84 - 96. 10.1016/j.conbuildmat.2017.10.001 . hal-01895423

\section{HAL Id: hal-01895423 \\ https://hal.science/hal-01895423}

Submitted on 15 Oct 2018

HAL is a multi-disciplinary open access archive for the deposit and dissemination of scientific research documents, whether they are published or not. The documents may come from teaching and research institutions in France or abroad, or from public or private research centers.
L'archive ouverte pluridisciplinaire HAL, est destinée au dépôt et à la diffusion de documents scientifiques de niveau recherche, publiés ou non, émanant des établissements d'enseignement et de recherche français ou étrangers, des laboratoires publics ou privés. 


\title{
Thermal, hydric and mechanical behaviours of adobes stabilized with
}

\section{cement}

\author{
Kalifala Dao ${ }^{1}$, Moussa Ouedraogo ${ }^{1,2}$, Younoussa Millogo ${ }^{1,2^{*}}$, Jean-Emmanuel Aubert $^{3}$ and \\ Moussa Gomina ${ }^{4}$ \\ ${ }^{1}$ Laboratoire de Chimie Moléculaire et des Matériaux (LCMM), UFR/ Sciences Exactes et Appliquées, \\ Université Ouaga I Pr Joseph KI-ZERBO, 03 B.P. 7021 Ouagadougou 03, Burkina Faso \\ ${ }^{2}$ Unité de Formation et de Recherche en Sciences et Techniques (UFR/ST), Université Nazi BONI, 01 BP 1091 \\ Bobo 01, Burkina Faso. \\ ${ }^{3}$ LMDC, Université de Toulouse, INSA, UPS, France. \\ ${ }^{4}$ Laboratoire CRISMAT UMR 6508 CNRS/ENSICAEN, 6 Bd Maréchal Juin, 14050 Caen Cedex 4, France
}

\begin{abstract}
The main objectives of this work were to manufacture adobes with good mechanical properties, even in a wet environment, and low thermal conductivity so as to give the population homes that provided better thermal comfort than cement-based constructions. For this purpose, clayey raw material from Burkina Faso, mainly composed of quartz (49 wt.\%), kaolinite (28 wt.\%), goethite (7 wt.\%) and muscovite (9 wt.\%) was mixed with up to 12 wt.\% of cement to manufacture adobes. Various characterization techniques were implemented to assess the microstructure of these materials: X-ray diffraction, infrared spectrometry, differential scanning calorimetry, scanning electron microscopy and energy dispersive spectrometry. Their physical properties were also investigated (through water absorption, spray test, apparent density, porosity and thermal conductivity) as their mechanical
\end{abstract}

\footnotetext{
${ }^{*}$ Corresponding author : Unité de Formation et de Recherche en Sciences et Techniques (UFR/ST), Université Nazi BONI, 01 BP 1091 Bobo 01, Burkina Faso.

Tel.: +226702633 83; fax: +22620982577.

E-mail address: millogokadi@gmail.com (Y. Millogo).
} 
characteristics (compressive and flexural strengths). It was found that the addition of cement resulted in the formation of calcium silicate hydrate (CSH) (I), ettringite and calcite. The CSH was formed partly through the hydration of anhydrous cement compounds (alite and belite) and also through pozzolanic reactions strongly involving finely crushed quartz and, to a lesser extent, kaolinite. These cement-stabilized adobes were particularly distinguished by good mechanical resistance even in a wet environment, and low thermal conductivity. These results indicate that adobes stabilized with $2 \mathrm{wt} . \%$ of cement are suitable for use as building materials for mass housing.

Keywords: Cement-stabilized adobes; Microstructure; Thermal conductivity; Hydric and mechanical properties.

\section{Introduction}

In Burkina Faso, a developing country in West Africa, most individual homes are built with adobes made with natural clayey soil, while more affluent populations use conventional materials such as concrete. The latter are being discarded today because of their high thermal conductivity but the utilization of geomaterials is hindered by their poor mechanical properties, which are very sensitive to humidity. The dried compressive strength of adobe can reach $4 \mathrm{MPa}$, which is high enough to allow building safely structures a few stairs high $[1,2]$. However their wet compressive strength is near zero: the buildings are eroded after each rainy season and their impermeability to water has to be restored. Generally, one of two methods is applied to improve the water resistance: protection of the walls with plaster, or stabilization of the adobes [3]. Traditionally, adobes are stabilized by adding a small amount of quicklime, cement, cow dung or natural fibres [4-18]. 
A large number of papers have reported the impact of cement or lime on some physical and mechanical properties of adobe blocks $[5,8,9,11,12]$ but little attention has been paid to their thermal and erosion properties. However, the thermal conductivity is a very important property in a dry climate as the production of adobes with low thermal conductivity can significantly reduce domestic energy consumption. Moreover, the production of adobes with good resistance to erosion avoids having to renew the plaster on the walls every year, which is time consuming and expensive.

In a previous study [12], adobes were manufactured with crushed clayey material with particle size of less than $0.315 \mathrm{~mm}$. In the present work, the adobes were manufactured with less finely crushed materials (particle size up to $5 \mathrm{~mm}$ ). It was thus possible to compare the effect of particle size between the two materials.

The objective of this work was to study the effect of cement admixture on the physical properties of adobes manufactured using clayey soil from Korsimoro in Burkina Faso, with a focus on the mechanical, thermal and erosion properties in relation with the mechanisms of calcium silicate hydrate $(\mathrm{CSH})$ formation. The influence of particle size on the mechanical properties of the adobes is discussed through its effect on CSH formation.

\section{Raw materials and experimental procedures}

\subsection{Raw materials}

The raw material used for manufacturing adobes was a brown clayey material from Korsimoro, a locality in the centre-north of Burkina Faso $\left(12^{\circ} 79^{\prime}\right.$ North and $-1^{\circ} 09^{\prime}$ West). This locality is exploited by farmers to make adobe for their houses.

The particle size distribution of the total sample after wet sieving for the coarser fraction $(\geq 80$ $\mu \mathrm{m})$ or the fine fraction $(<80 \mu \mathrm{m})$ obtained after sedimentation was implemented according to 
standards NF P 94-056 and NF P 94-057, respectively. Figure 1 presents the particle size distribution of the sample. Careful examination of this curve shows that the sample was composed of 4.7 wt.\% coarse sand, 37.9 wt.\% fine sand $(20-200 \mu \mathrm{m}) 22.7$ wt.\% silt $(2-20 \mu \mathrm{m})$ and 29.9 wt.\% clay $(<2 \mu \mathrm{m})$. The Atterberg's limits are used to appreciate the soil plasticity for its efficient using in civil engineering. The Atterberg's limits are soil water content during its different phases transitions (liquid, plastic and solid). Liquid limit $\left(\mathrm{W}_{\mathrm{L}}\right)$ is the soil water content during its transformation from liquid state to plastic state. The liquid limit was measured by the method of the dish of Casagrande. Plastic limit is soil water content during its transformation from plastic state to solid state. The plasticity limit was measured by the method of the roller $\left(\mathrm{W}_{\mathrm{P}}\right)$. The plasticity index $(\mathrm{PI})$ represents the broad of the plasticity domain and is the difference between liquid limit and plasticity limit. These limits measures were realized according to NF P94-051 standard. The liquid limit $\left(\mathrm{w}_{\mathrm{L}}\right)$, plasticity limit $\left(\mathrm{w}_{\mathrm{P}}\right)$ and the plasticity index (PI) of the studied sample were 31, 17 and 14\%, respectively. In order to appreciate its suitability for the manufacture adobe bricks, the liquid limit and plasticity index are presented in the diagram of Figure 2, which was defined by the "Centre International de la Construction en Terre, CRATerre-EAG" to compare the different materials used for manufacturing compressed earth blocks (CEB). The point representing the plasticity index and liquid limit of the material is located in the area of soils recommended for adobe manufacture. The methylene blue value of the raw material, obtained according to standards NF P 94-068, was $5.17 \mathrm{~g} / 100 \mathrm{~g}$, meaning that this sample was a silty clayey material with medium plasticity. This was corroborated by the particle size distribution.

The cement used for this study (artificial Portland cement type CEMI) was manufactured by Diamond Cement in Burkina Faso. Its chemical, mineralogical and physical characteristics are given in Table 1 [19]. 


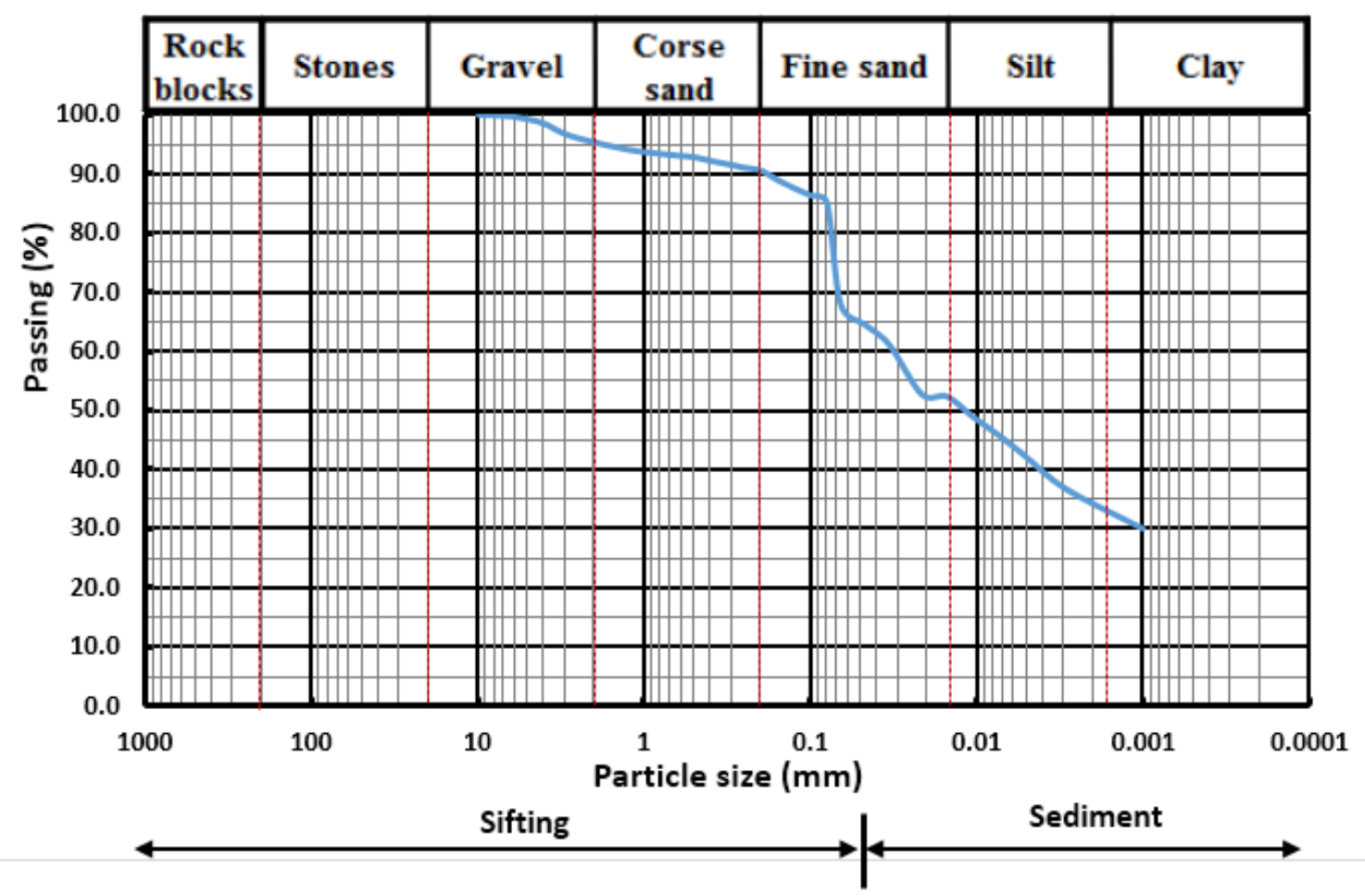

Figure 1: Particle size distribution of the sample

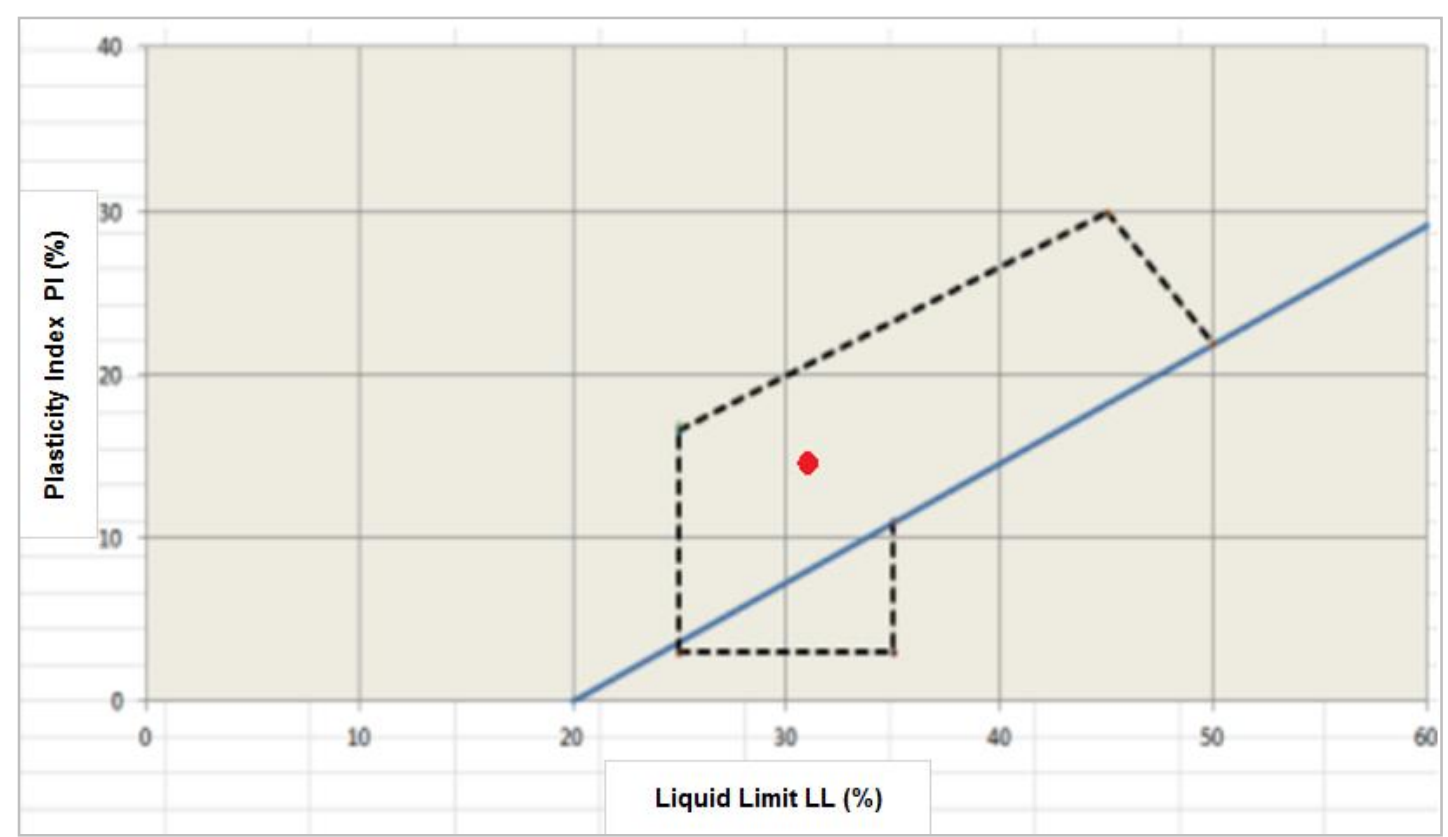

Figure 2: Position of sample in CRATerre-EAG diagram 
Table 1: Chemical and mineralogical compositions, and some physical properties of the cement used in this work

\begin{tabular}{|c|c|c|c|c|c|c|c|c|c|c|c|c|}
\hline \multirow{2}{*}{$\begin{array}{l}\text { Chemical } \\
\text { Composition } \\
\text { (wt.\%) }\end{array}$} & $\mathrm{SiO}_{2}$ & $\mathbf{A l}_{2} \mathbf{O}_{3}$ & $\mathrm{Fe}_{2} \mathrm{O}_{3}$ & MgO & $\mathrm{CaO}$ & $\mathbf{P}_{2} \mathbf{O}_{5}$ & $\mathrm{SO}_{3}$ & $\mathrm{Na}_{2} \mathrm{O}$ & $\mathrm{K}_{2} \mathbf{O}$ & F.L. & I.R. & L.O.I. \\
\hline & 20.12 & 5.73 & 4.06 & 1.18 & 64.82 & 0.39 & 2.68 & 0.08 & 0.17 & 0.80 & 0.28 & 0.27 \\
\hline \multirow{2}{*}{$\begin{array}{l}\text { Mineralogy } \\
(\text { wt.\%) }\end{array}$} & \multicolumn{3}{|c|}{$\mathrm{C}_{3} \mathrm{~S}$} & \multicolumn{3}{|c|}{$\mathrm{C}_{2} \mathrm{~S}$} & \multicolumn{3}{|c|}{$\mathbf{C}_{3} \mathbf{A}$} & \multicolumn{3}{|c|}{$\mathrm{C}_{4} \mathrm{AF}$} \\
\hline & \multicolumn{3}{|c|}{55.70} & \multicolumn{3}{|c|}{15.70} & \multirow{2}{*}{\multicolumn{2}{|c|}{$\frac{8.30}{\text { ity }\left(\mathrm{g} / \mathrm{cm}^{3}\right)}$}} & & \multicolumn{3}{|c|}{12.30} \\
\hline Physical & \multicolumn{3}{|c|}{ Specific density $\left(\mathrm{g} / \mathrm{cm}^{3}\right)$} & & \multirow{2}{*}{\multicolumn{4}{|c|}{$\frac{\text { Apparent density }\left(\mathrm{g} / \mathrm{cm}^{3}\right)}{1.06}$}} & \multicolumn{4}{|c|}{ Setting time (h) } \\
\hline Properties & \multicolumn{3}{|c|}{3.02} & 1.06 & & & & & & \multicolumn{3}{|c|}{3.00} \\
\hline
\end{tabular}

FL: Free lime; LOI: Loss On Ignition; IR: Insoluble Residues

$\mathrm{C}_{3} \mathrm{~S}$ : Alite; $\mathrm{C} 2 \mathrm{~S}$ : Belite; $\mathrm{C}_{3} \mathrm{~A}$ : Celite and $\mathrm{C}_{4} \mathrm{AF}$ : Ferrite

\subsection{Experimental methods}

The clayey material was first dried at $105^{\circ} \mathrm{C}$ for $24 \mathrm{~h}$ and crushed to obtain particles $<5$ mm. It was then mixed with different amounts of cement (up to $12 \%$ by weight) at a water content giving the optimum workability of the paste. The water amount (W) in the mixture was expressed in $\mathrm{mL}$ as a function of the weight of clayey material (A) and the weight of cement $(\mathrm{C})$ according to the empirical relation: $\mathrm{W}=0.2 * \mathrm{~A}+0.4 * \mathrm{C}$ (relation 1 ) from Boffoué et al.(2015) [20].

The water amount calculated above gave a paste suitable for the manufacture of cementadded adobes. The pastes obtained were homogenized for $15 \mathrm{~min}$, manually pressed in two layers with 60 shocks for each layer in prism moulds $\left(4 \times 4 \times 16 \mathrm{~cm}^{3}\right)$ and kept at an average temperature of $25^{\circ} \mathrm{C}$ for $24 \mathrm{~h}$ in the test room. The as-moulded adobes were stored for 28 days at a constant temperature of $20^{\circ} \mathrm{C}$ in the curing room.

The compressive and flexural strengths were measured by using a hydraulic press equipped with a $200 \mathrm{kN}$ load cell at a controlled displacement rate of $0.5 \mathrm{~mm} / \mathrm{min}$ according to standards NF P18-406. The experimental conditions used for compressive tests have significant effects on the measured value of the compressive strength [21]. For these tests, the samples were cured in an air-conditioned room at $20^{\circ} \mathrm{C}$ and $50 \%$ relative humidity until their 
mass was constant. The samples were directly tested between the plates of the press without any specific precautions to limit the confinement during the test [22]. The adobe water absorption by capillarity was evaluated on a cured specimen according to standards NF EN 1015-18

For the spray test, the specimens were tilted at $30^{\circ}$ to the vertical and water was sprayed onto the surface in fine droplets for 10 minutes, under a pressure of 2 bars. The closed porosity $(\mathrm{P})$ was calculated using the relation:

$\mathrm{P}(\%)=\left(1-\mathrm{d}_{\mathrm{a}} / \mathrm{d}_{\mathrm{s}}\right) * 100($ relation 2$)$

where $d_{a}$ is the apparent density and $d_{s}$ the absolute density $\left(\mathrm{g} / \mathrm{cm}^{3}\right)$.

The thermal conductivity $(\lambda)$ of the adobes was measured using a TR-1 probe $(2.4 \mathrm{~mm}$ diameter, $10 \mathrm{~cm}$ length, working range: 0.1 to $4 \mathrm{Wm}^{-1} \mathrm{~K}^{-1}$ ) connected to a $\mathrm{KD} 2$ Thermal Pro Properties Analyser. The probe was introduced into a hole made in the centre of the test piece so that it was not in contact with the air. This method for measuring thermal conductivity is operational regardless of the moisture content. The thermal conductivity is measured at around $35^{\circ} \mathrm{C}$ in laboratory in April 2016 (the most heated month in Burkina Faso) with average relative humidity of $52 \%$. This relative humidity value is given by our meteorology department. These conditions have been imposed in other to take into account the climatic reality of our country.

The chemical composition of the clayey raw material was estimated on digested crushed samples with size $<80 \mu \mathrm{m}$ by Inductively Coupled Plasma - Atomic Emission Spectrometry (ICP-AES). The loss on ignition was evaluated by sample calcination up to $1000^{\circ} \mathrm{C}$.

X-Ray diffraction (XRD), differential scanning calorimetry (DSC), thermal gravimetric analysis (TGA) and infra-red spectroscopy (IR) tests were implemented on the fraction of material with size $<80 \mu \mathrm{m}$ to study the mineralogical composition of the raw material and the materials mixed with cement. For XRD, a Brüker D 5000 apparatus equipped with a copper 
$\mathrm{K} \alpha(\lambda=1.54 \AA)$ anticathode was used. The mineralogical composition of the raw sample was obtained by using XRD and the results of the chemical analyses. For a chemical element "a", the following relation was used to calculate the amount T (a) of oxide (wt. \%):

$T(a)=\sum M_{i} P_{i}(a)($ relation 3$)$

where $\mathrm{M}_{\mathrm{i}}$ is the amount (in wt.\%) of mineral $i$ in the material under study; $\mathrm{P}_{\mathrm{i}}$ (a) is the proportion of element $a$ in the mineral $i$.

DSC and TGA were carried out on crushed samples heated to $1000^{\circ} \mathrm{C}$ at a constant rate of $10^{\circ} \mathrm{C} / \mathrm{min}$ using a Netzsch SATA 449 F3 Jupiter apparatus. The IR spectra were obtained using a Perkin Elmer UATR1 Frontier FT-IR spectrometer in the range 4000 to $550 \mathrm{~cm}^{-1}$. A JEOL 6380 LV apparatus equipped with a backscattered electron (BSE) detector was used for scanning electron microscopy (SEM) observations on freshly fractured pieces of adobes. The elemental quantitative analyses were performed by the energy dispersive spectrometry (EDS) technique using a Brïer X Flash 6/30 detector. The morphology of the samples was analysed using a Keyence VH-5911 video optical microscope.

\section{Results and discussion}

\subsection{Chemical and mineralogical characterization}

The chemical composition of the sample is presented in Table 2. The sample contained large amounts of silica, alumina and iron oxides and a small amount of potassium oxide. These results suggested that the sample contained clayey minerals, quartz and iron minerals. 
The XRD pattern of the sample is presented in Figure 3. This diagram shows that the raw material contained kaolinite, quartz, goethite and muscovite. This result correlates well with those for the chemical composition.

The DSC and TGA curves of the sample are given in Figure 4. They show endothermic peak around $96.4^{\circ} \mathrm{C}$ associated with a mass loss of $1.2 \mathrm{wt} . \%$. The endothermic peak around $399^{\circ} \mathrm{C}$ can be attributed to the dehydroxylation of goethite and its transformation into hematite. The strong endothermic phenomenon occurring at $518^{\circ} \mathrm{C}$ is linked to the dehydroxylation of kaolinite and its transformation into metakaolinite. This phenomenon is followed by 3.4 wt. $\%$ mass loss. It appears at low temperature (less than $600^{\circ} \mathrm{C}$ ) because of the low crystallinity of the kaolinite, which could be disordered. The weak endothermic peak around $576^{\circ}$ is related to the transformation of quartz $\alpha$ to quartz $\beta$. The last exothermic peak around $920^{\circ} \mathrm{C}$ is attributable to the structural reorganization of metakaolinite.

Concerning the IR investigations on the raw material (Figure 5), the spectrum shows bands of quartz (Si-O vibration at $\left.1030 \mathrm{~cm}^{-1}\right)$; of kaolinite: 3620,3650 and $3690 \mathrm{~cm}^{-1}(\mathrm{O}-\mathrm{H}$ stretching vibrations); $1116,1005 \mathrm{~cm}^{-1}$ (Si-O vibrations); $914 \mathrm{~cm}^{-1}$ (Al-OH bending vibration) and hygroscopic water $\left(1637 \mathrm{~cm}^{-1}\right)$. The absence of the kaolinite band at $3672 \mathrm{~cm}^{-1}$ confirms its low crystallinity in the sample [23, 24].

The mineralogical composition of the raw material was evaluated using relation (3). The sample was rich in quartz (49 wt.\%) and kaolinite (28 wt.\%) but poor in muscovite (9 wt.\%) and goethite $(7$ wt.\%). These results correlate with sample grain size distribution, which showed that the studied is rich in clayey material and sand (mainly the quartz). 
Table 2: Chemical composition of the raw material

\begin{tabular}{|l|c|c|c|c|c|c|c|c|c|c||c|}
\hline Oxides & $\mathrm{SiO}_{2}$ & $\mathrm{Al}_{2} \mathrm{O}_{3}$ & $\mathrm{Fe}_{2} \mathrm{O}_{3}$ & $\mathrm{MnO}$ & $\mathrm{MgO}$ & $\mathrm{CaO}$ & $\mathrm{Na}_{2} \mathrm{O}$ & $\mathrm{K}_{2} \mathrm{O}$ & $\mathrm{TiO}_{2}$ & $\mathrm{P}_{2} \mathrm{O}_{5}$ & L.O.I. \\
\hline Wt.\% & 66.13 & 14.38 & 6.68 & 0.15 & 0.45 & 0.41 & 0.24 & 1.00 & 1.09 & 0.06 & 8.93 \\
\hline
\end{tabular}

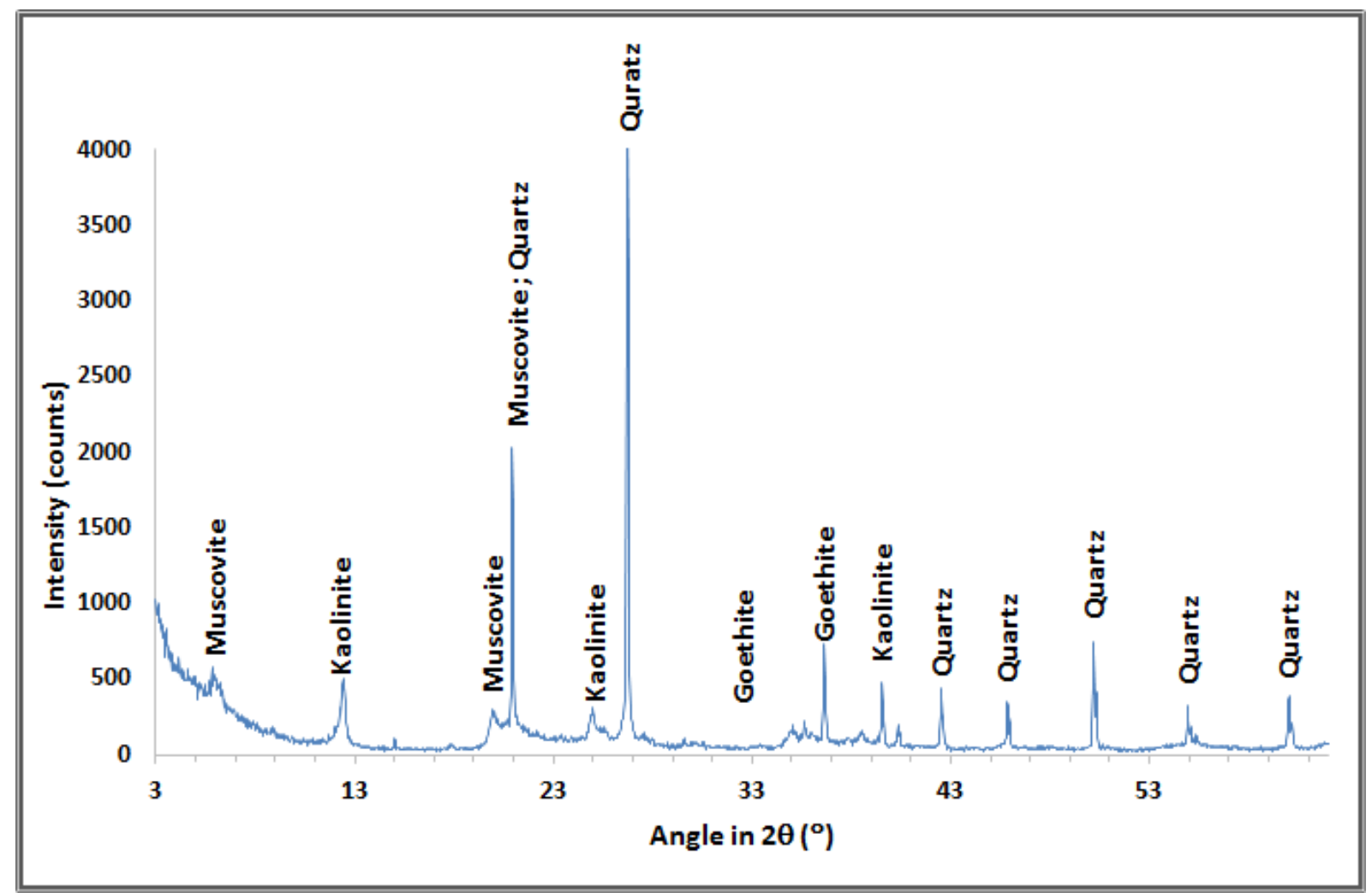

Figure 3: X-ray diffraction pattern of the raw material 


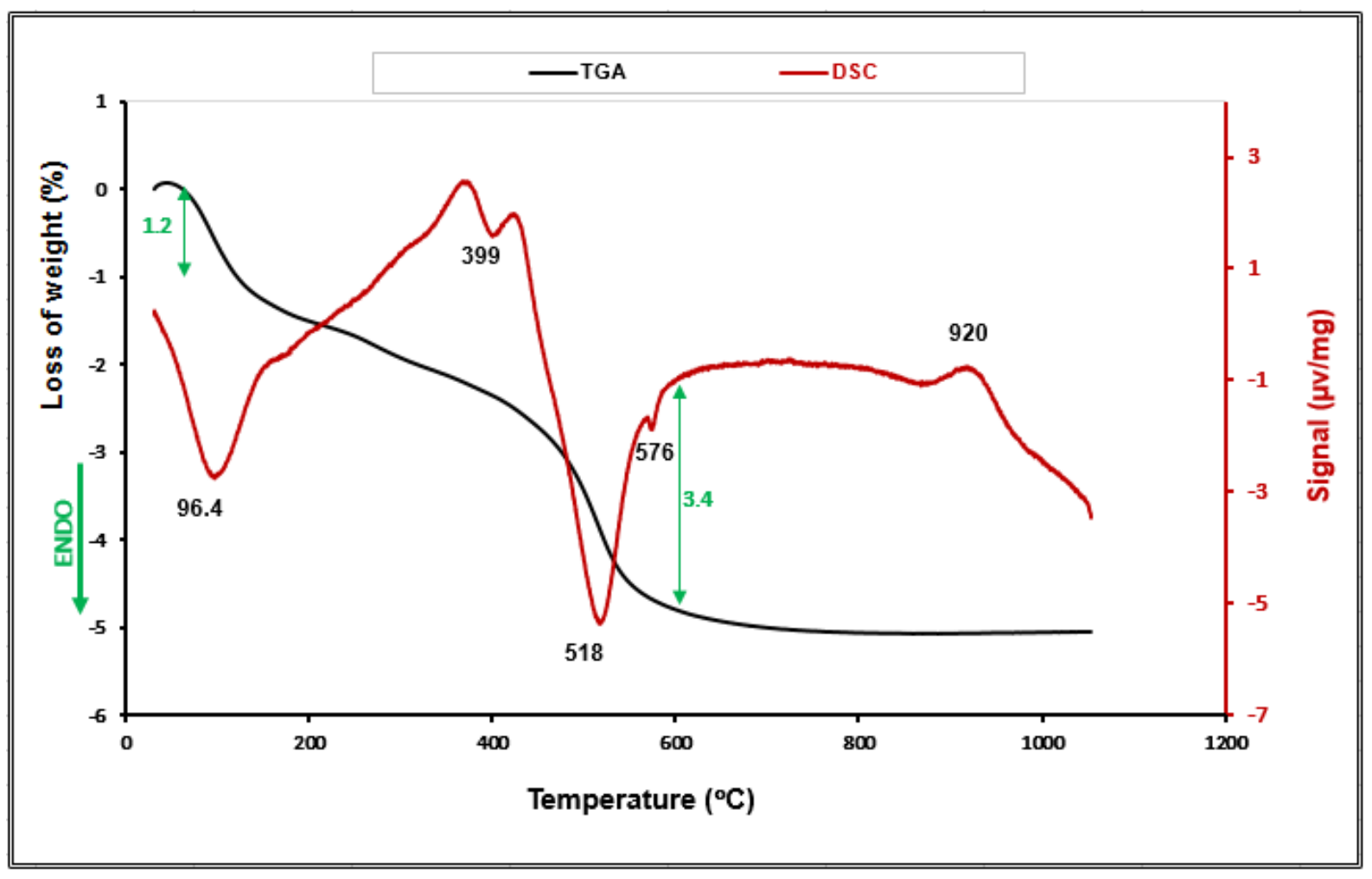

Figure 4: DSC-TGA of the raw material

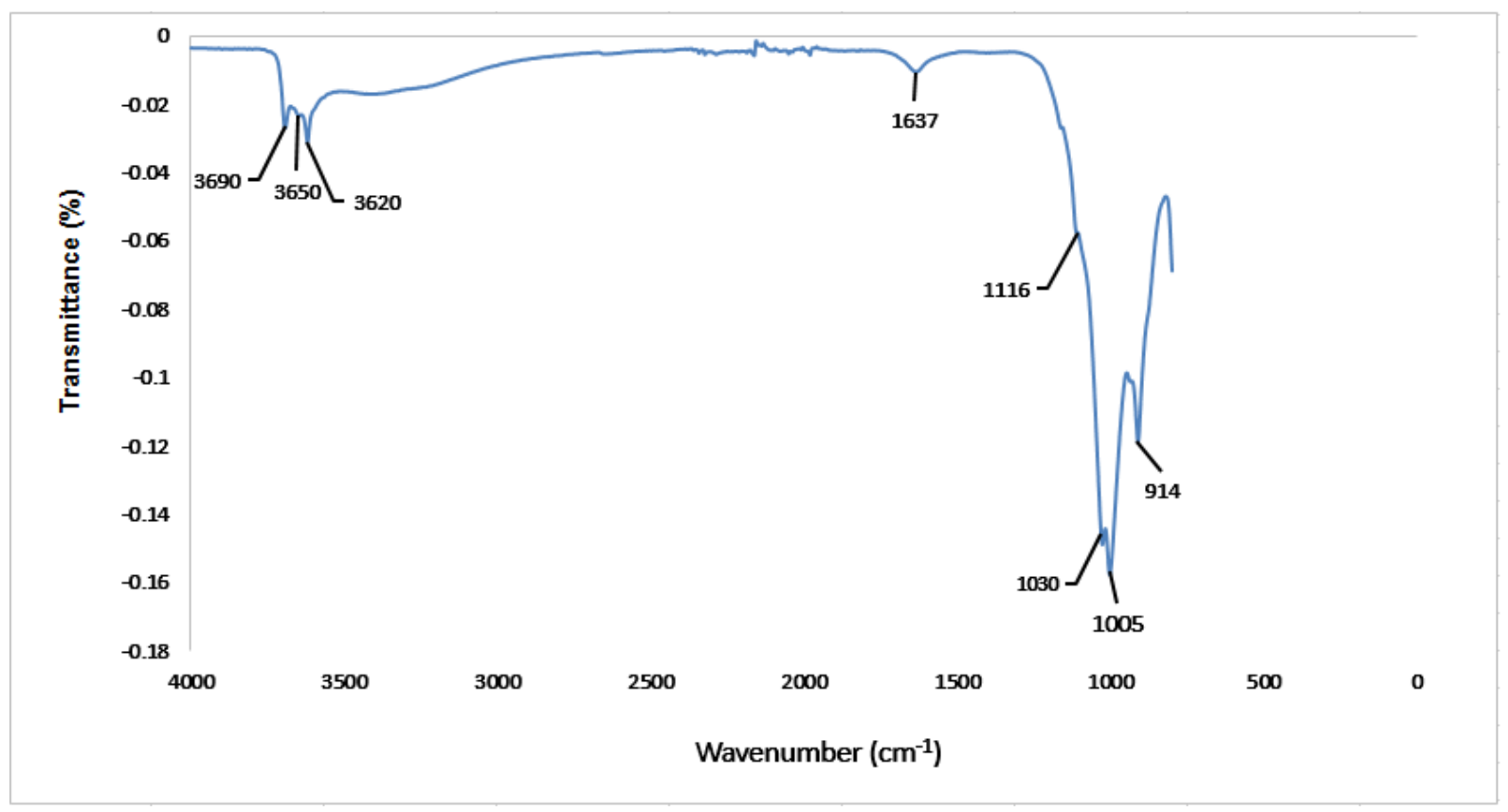

Figure 5: FTIR diagram of the raw material 


\subsection{Microstructure of the cement-containing materials}

Typical XRD patterns of cement-clayey material mixtures are given in Figure 6. An overall analysis of these patterns shows that the mixtures consist of the original minerals (kaolinite, quartz, goethite and muscovite) and calcite, the latter coming from the carbonation of portlandite obtained by hydration of alite $\left(\mathrm{C}_{3} \mathrm{~S}\right)$ and belite $\left(\mathrm{C}_{2} \mathrm{~S}\right)$ with carbon dioxide in the air. To evidence the amorphous phases formed, crushed adobe samples were analysed by DSC and FTIR spectrometry. The DSC curves of Figure 7 reveal the main thermal phenomena occurring in the raw material. The cement-containing adobes show a broad endothermic phenomenon at around $110-150{ }^{\circ} \mathrm{C}$ due to the loss of structural water of the calcium silicate hydrate $(\mathrm{CSH})[25,26]$. The endothermic peak at about $700^{\circ} \mathrm{C}$ relates to the decomposition of calcite into quicklime $(\mathrm{CaO})$. The infra-red spectra of the samples of Figure 8 display the bands of the raw material and the bands located at 874 and $1450 \mathrm{~cm}^{-1}$, which indicate the presence of calcite [27]. The presence of calcite is confirmed by the intensification of the band at $3652 \mathrm{~cm}^{-1}$ [28]. The intensity of the broad stretching vibration at around $3400 \mathrm{~cm}^{-1}$ increases This result suggests that the former band was due to the vibrations of the hydroxide of CSH [19, 27-29] and of the physisorbed water. 


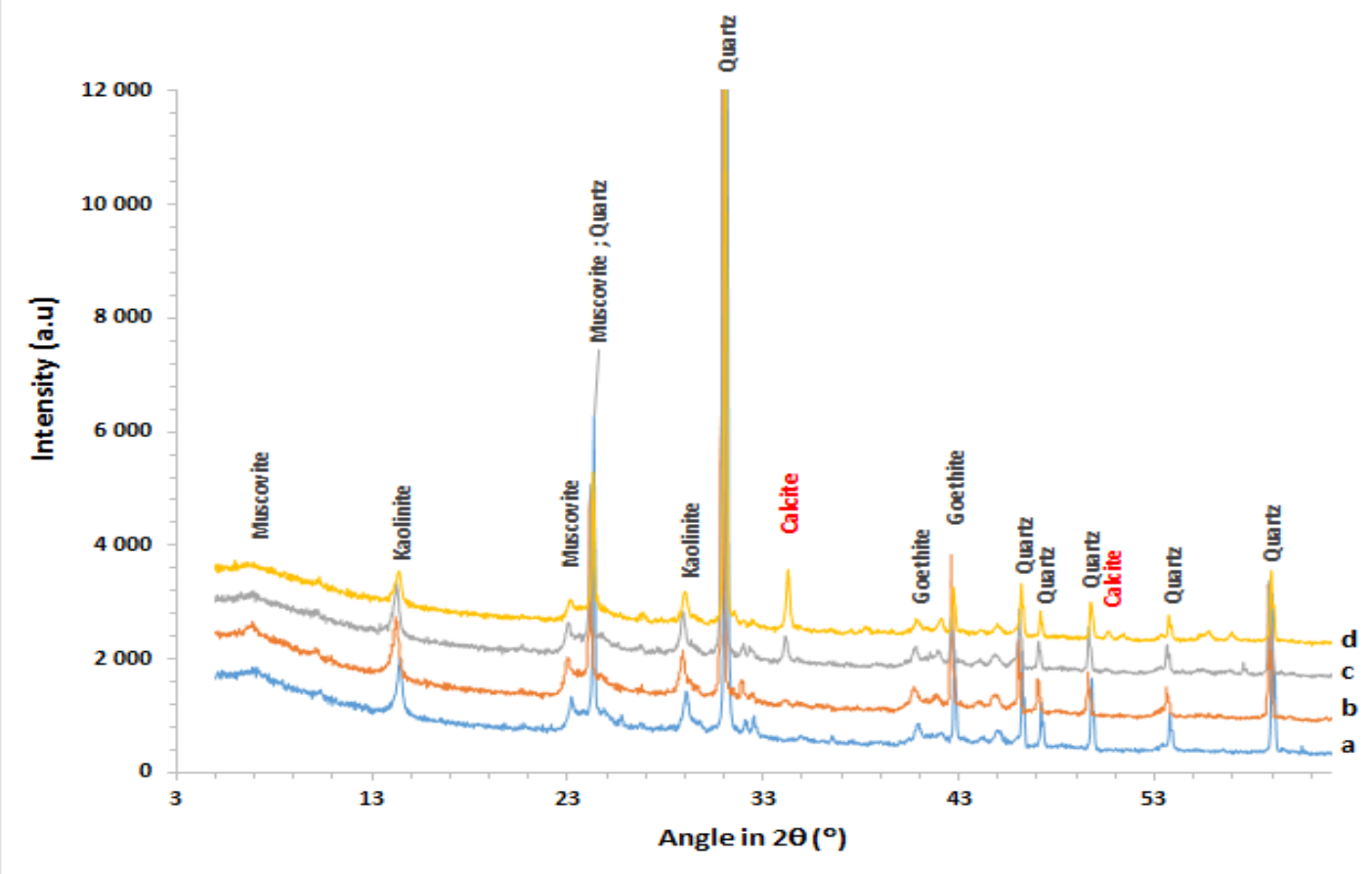

Figure 6: X-ray diffraction patterns of the samples

a) raw material; adobe with b) $2 \mathrm{wt} . \%$ cement, c) $4 \mathrm{wt} . \%$ cement, d) $12 \mathrm{wt} . \%$ cement

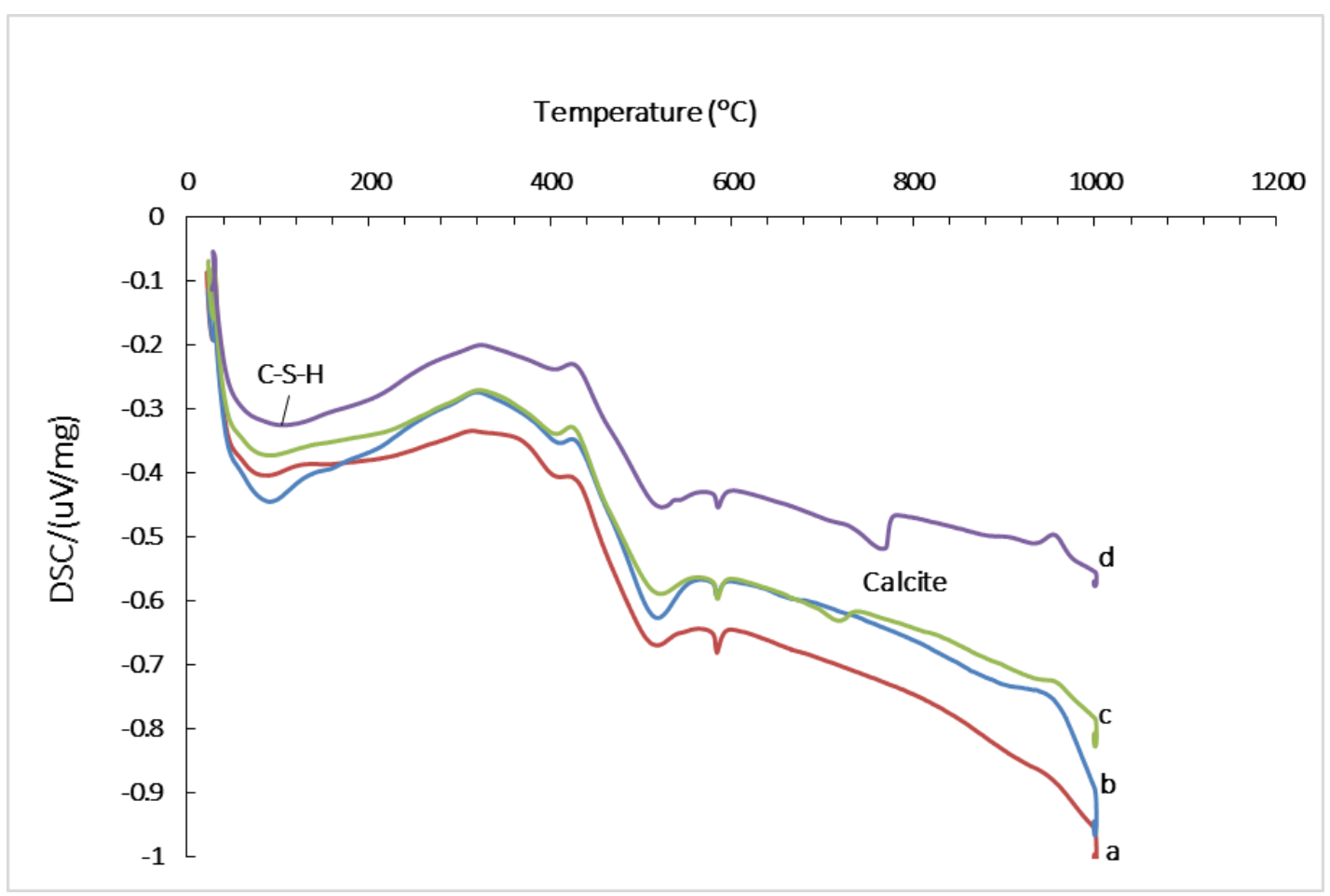

Figure 7: DSC of the samples

a) raw material, and adobes with b) 2 wt.\% cement, c) 4 wt.\% cement, d) 12 wt.\% cement 


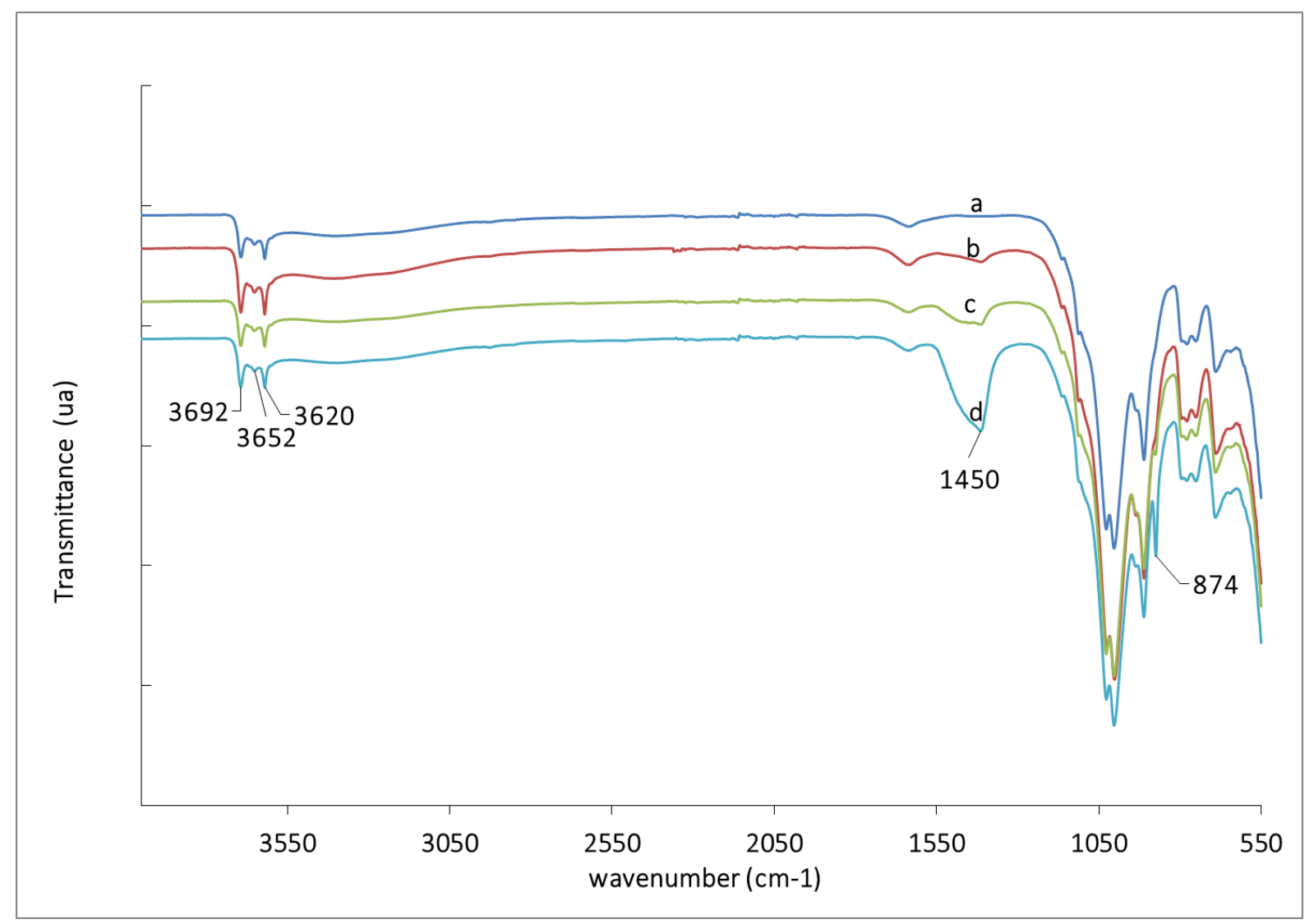

Figure 8: FT infra-red spectra of the samples (a: raw material; b: material with 2 wt.\% cement, c: 4 wt. \% cement, d: 12 wt.\% cement)

To highlight the CSH formation, the evolutions of the intensities of the kaolinite basal peak $\left(2 \theta=14^{\circ}\right)$ and of the prominent peak of quartz $\left(2 \theta=31^{\circ}\right)$ were investigated versus the cement content. The intensity decreased for both peaks when the cement content was increased (Figure 9). It can be concluded that the kaolinite and mainly the crushed fine quartz reacted with portlandite (produced by the hydration of anhydrous components of the cement such as alite and belite) through a pozzolanic reaction. Crushing fine quartz process activates quartz by increasing of its specific area and this condition with test temperature (around $35^{\circ} \mathrm{C}$ ), could be in the favor of quartz dissolution. In these conditions, CSH could be formed. For these two cases, solubilization of crushed silica may occur in a basic medium and this hypothesis is supported by Figure 10, which shows that $\mathrm{pH}$ increases when the cement content rises [30]. The solubilization of silica from the kaolinite is facilitated by the disordered 
structure of the kaolinite. The CSH formation by this synthesis route is reported by Millogo's et al. (2008) [11] in similar work. The implied reactions for CSH formation can be summarized as follows:

$\mathrm{Ca}(\mathrm{OH})_{2} \rightleftarrows \mathrm{Ca}^{2+}+2 \mathrm{OH}^{-}$(portlandite dissociation in aqueous medium)

In a basic medium, we have:

$\mathrm{SiO}_{2}$ (crushed quartz or silica from kaolinite) $+2 \mathrm{OH}^{-} \rightarrow \mathrm{H}_{2} \mathrm{SiO}_{4}{ }^{2-}$ (reaction 1)

In presence of calcium ions in solution it follows:

$\mathrm{xCa}^{2+}+\mathrm{H}_{2} \mathrm{SiO}_{4}{ }^{2-}+2(\mathrm{x}-1) \mathrm{OH}^{-}+\mathrm{y} \mathrm{H}_{2} \mathrm{O} \rightarrow \mathrm{C}-\mathrm{S}-\mathrm{H}$ (reaction 2$)$

The calcium silicate hydrate $(\mathrm{CSH})$ is also directly obtained by hydration of alite $\left(\mathrm{C}_{3} \mathrm{~S}\right)$ and belite $\left(\mathrm{C}_{2} \mathrm{~S}\right)$ according to the well-known reactions:

$$
\begin{aligned}
& 2 \mathrm{C}_{3} \mathrm{~S}+6 \mathrm{H} \rightarrow \mathrm{C}_{3} \mathrm{~S}_{2} \mathrm{H}_{3}(\mathrm{C}-\mathrm{S}-\mathrm{H})+3 \mathrm{CH} \text { (reaction 3) } \\
& \left.2 \mathrm{C}_{2} \mathrm{~S}+4 \mathrm{H} \rightarrow \mathrm{C}_{3} \mathrm{~S}_{2} \mathrm{H}_{3}(\mathrm{C}-\mathrm{S}-\mathrm{H})+\mathrm{CH} \text { (reaction } 4\right)
\end{aligned}
$$

where $\mathrm{H}$ stands for $\mathrm{H}_{2} \mathrm{O}, \mathrm{C}_{2} \mathrm{~S}$ for $2 \mathrm{CaO} . \mathrm{SiO}_{2}, \mathrm{C}_{3} \mathrm{~S}$ for $3 \mathrm{CaO} . \mathrm{SiO}_{2}$ and $\mathrm{CH}$ for portlandite. 


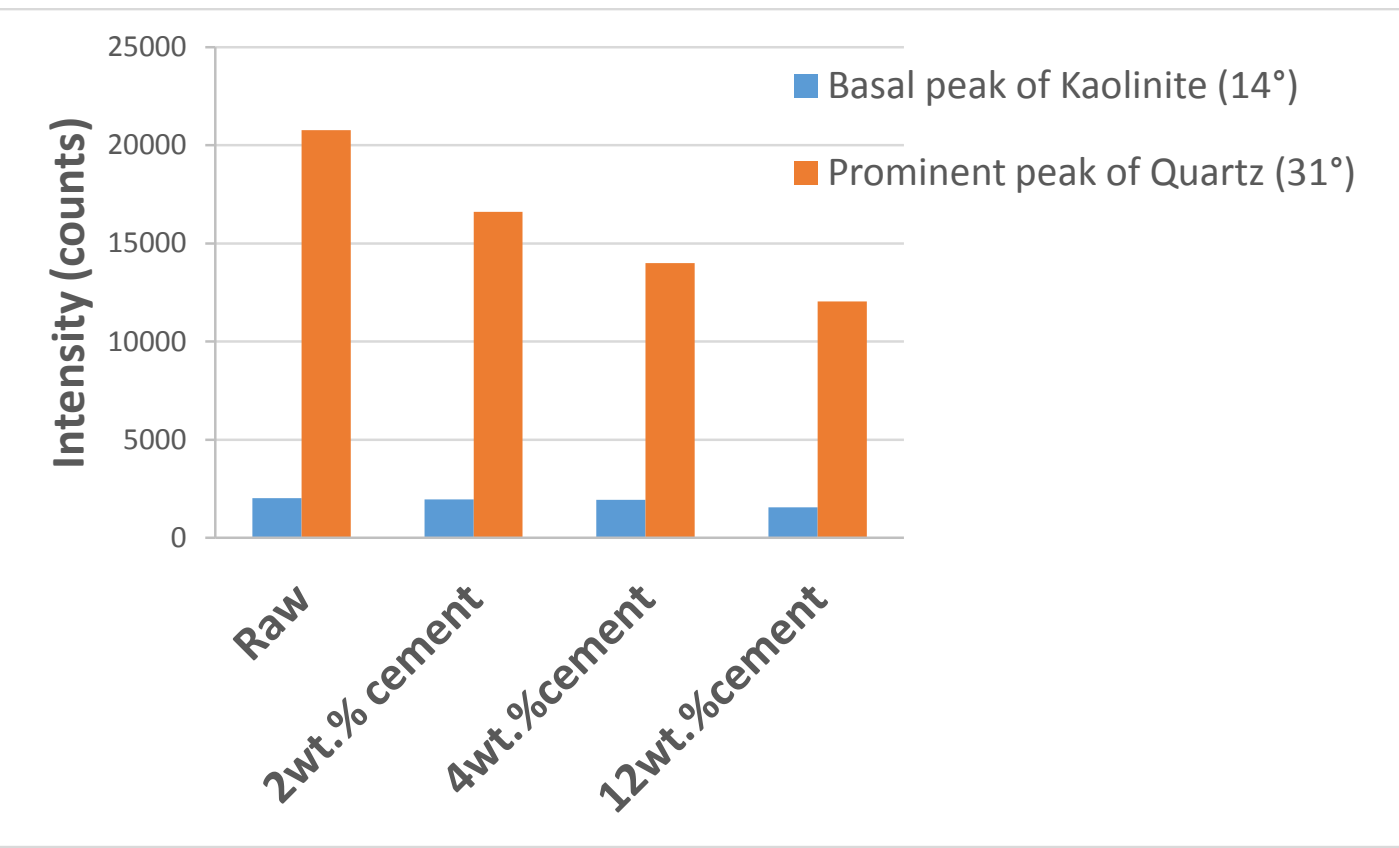

Figure 9: Evolutions of the basal peak of kaolinite and the prominent peak of quartz versus cement content

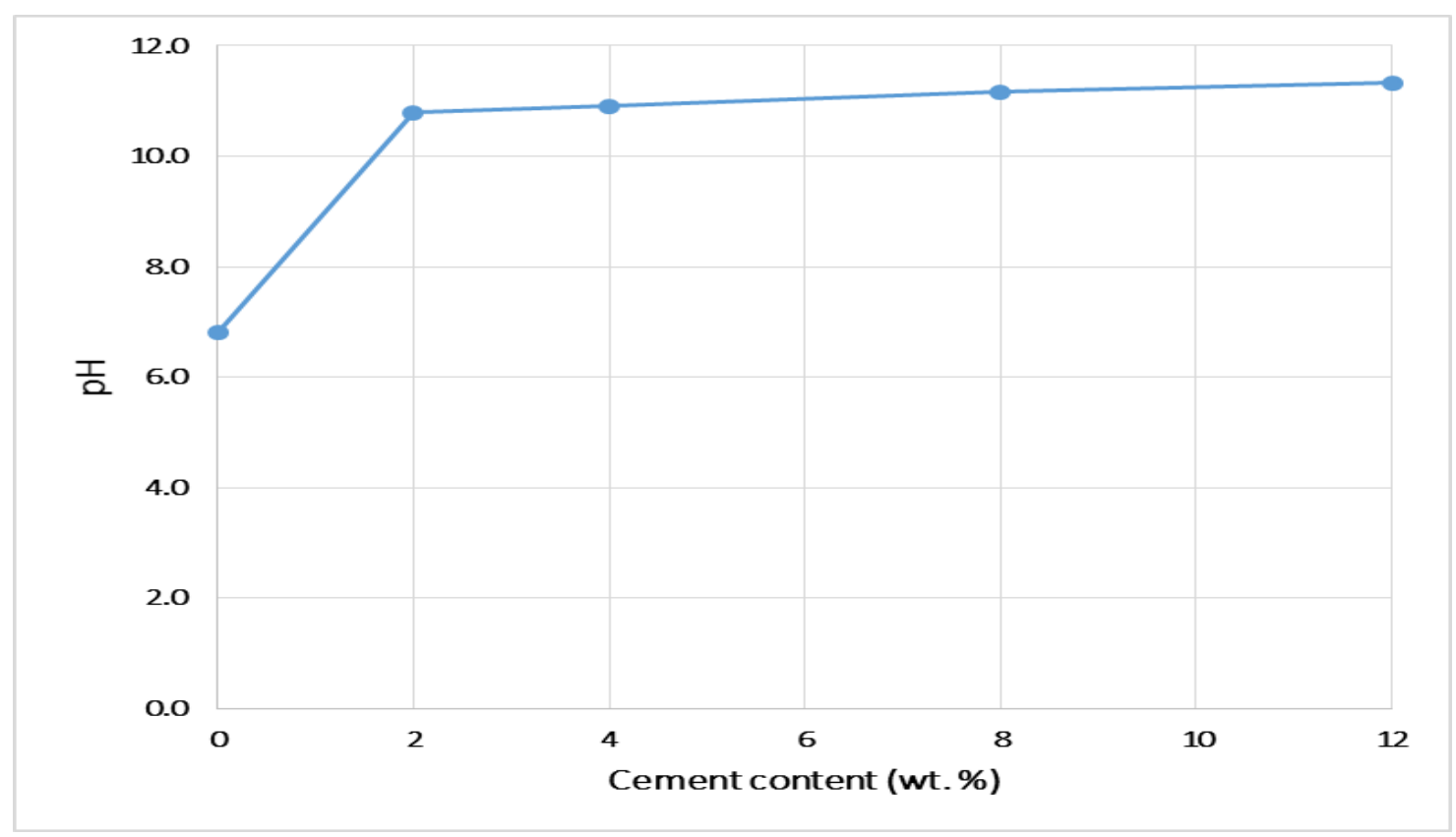

Figure 10 : pH vs. cement content

The plots presented in Figures 9 and 10 show that a noteworthy pozzolanic reaction takes place between portlandite and quartz (the raw material contains 37.9 wt. \% of fine sand) to produce $\mathrm{CSH}$, whereas this reaction is much less marked with kaolinite. The prominent 
peak of quartz decreases up $42 \%$ when the adobe is amended with 12 wt.\% cement, whereas the basal peak of kaolinite decreases only by $23 \%$ for the same formulation. It can be concluded that production of the large amount of $\mathrm{CSH}$ by pozzolanic reaction involves fine crushed quartz. The formation of $\mathrm{CSH}$ through reactions 2, 3 and 4 helps to improve the physical and the mechanical properties of the adobes.

SEM observations associated with EDS analyses of freshly fractured pieces of adobes were performed to assess the microstructure and the morphology of the CSH. Figure 11 shows the micrographs of the different adobes and Figure 12 presents the EDS spectra corresponding to the points mentioned on the SEM images. Analysis of the cement-free adobe (Figure 11a Zone A, Figure 12A) reveals a heterogeneous microstructure consisting of isolated particles of kaolinite, quartz and goethite, and having large pores. With cement-containing adobes, the microstructure is more homogeneous with fewer large size pores and the isolated particles observed in raw adobe are linked between them.

Adobes with 2 wt.\% cement show bright areas (Figure 11b - Zone B, Figure 12B) identified as a mixture of kaolinite, quartz, goethite and calcic-compounds (calcite and/or CSH). Quartz grains and a small amount of goethite are present (Figure 11b - Zone C, Figure 12C). With 4 wt.\% cement, the pore size is strongly reduced (Figure 11c). The bright areas developed are associated with the presence of kaolinite, quartz goethite, calcite and/or CSH (Figure 11c - Zone D, Figure 12D). Also, in these areas, sulfur compounds like ettringite were detected, which may have formed through the reaction between gypsum and $\mathrm{C}_{3} \mathrm{~A}$ in aqueous medium. The adobes containing $12 \mathrm{wt} \%$ cement exhibit large bright areas (Figure 11d - Zone E; Figure 11d - Zone F; Figure 12E; Figure 12F). According to the $\mathrm{Ca} / \mathrm{Si}$ ratio, which is 0.69 for zone $\mathrm{E}$ and 0.50 for zone $\mathrm{F}$, these areas are rich in $\mathrm{CSH}$ [31- 33]. The slight difference with respect to ratios reported in the literature for Zone $\mathrm{F}$ is due to the 
presence of a small amount of kaolinite in this area. Considering the $\mathrm{Ca} / \mathrm{Si}$ ratios, it could be suggested that this CSH is $\alpha \mathrm{CSH}$ or CSH (I) [31- 33].
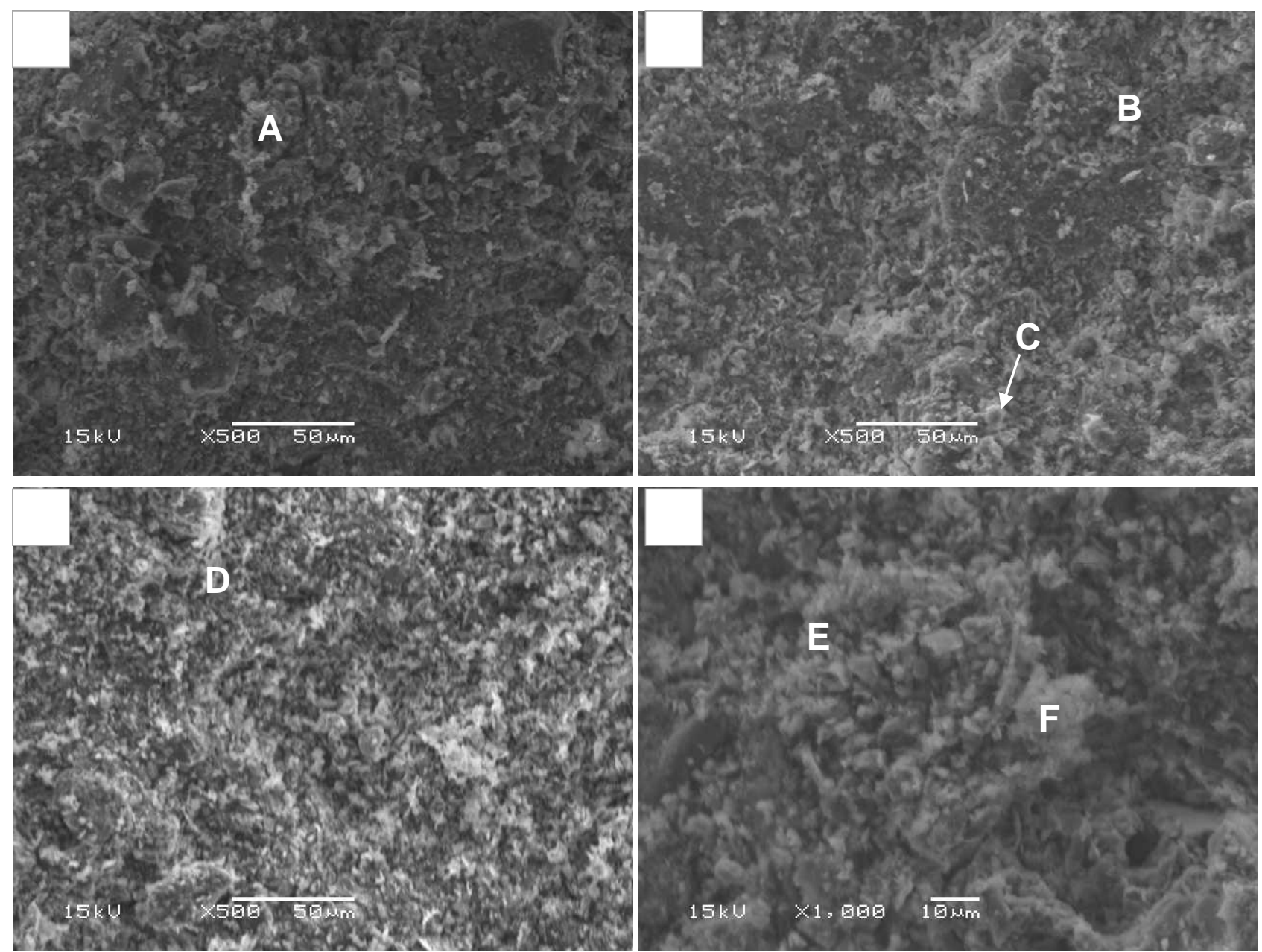

Figure 11: SEM micrographs of adobe samples

(a) raw adobe; adobe with: 2 wt.\% cement (b), 4 wt.\% cement (c) and 12 wt.\% cement (d). 

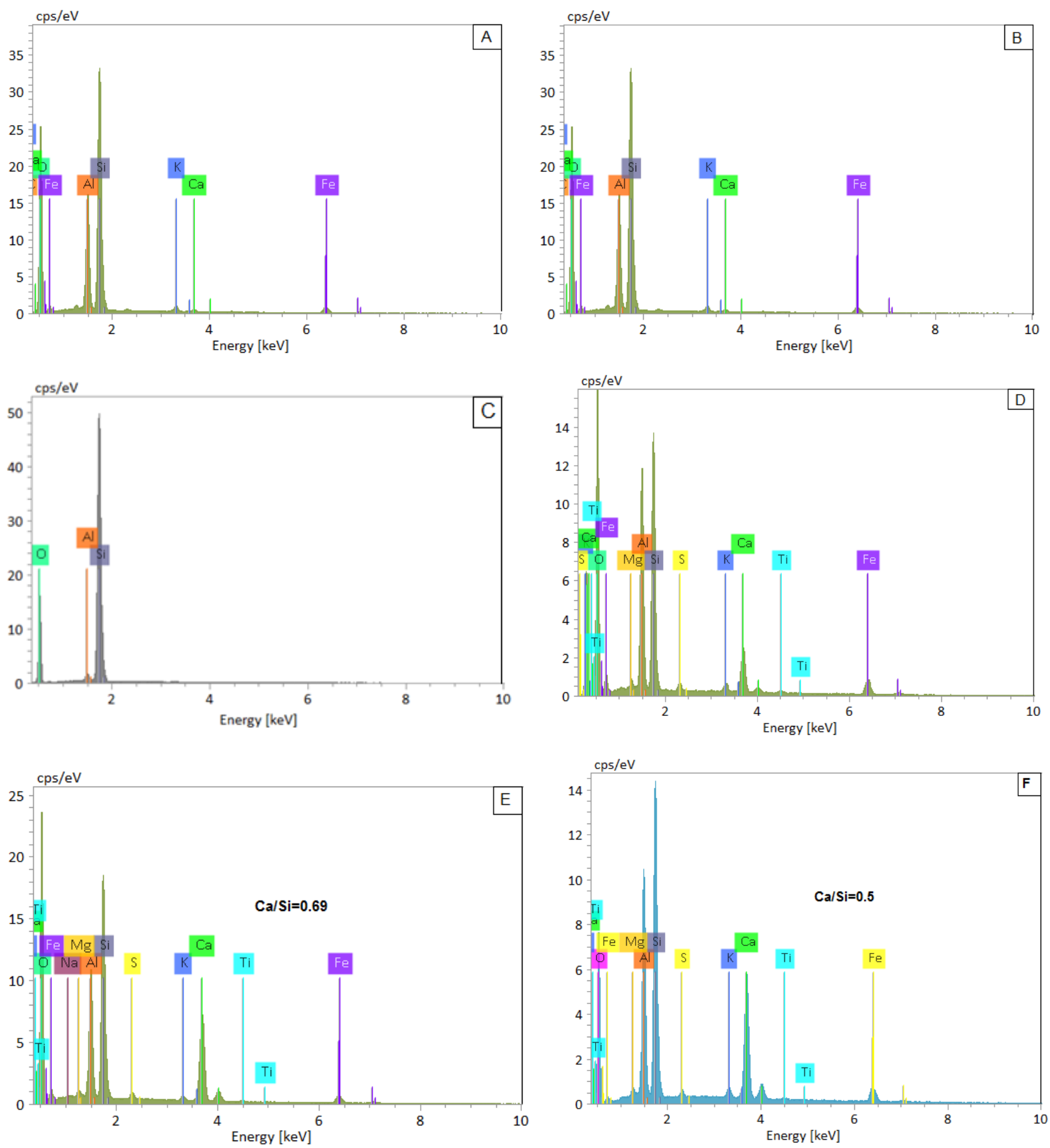

Figure 12: EDS analyses of areas marked in Figure 14

\subsection{Effect of cement on the physical and mechanical properties of adobes}

Video optical microscopy and SEM images were used to highlight the effect of cement on the microstructure of the adobes. Optical microscopy revealed a heterogeneous microstructure with the presence of a high density of large pores in the cement-free adobes (Figure 13a). 
Void ratio decreased drastically when the cement content was increased (Figures13 b-d), hence the microstructure was more homogeneous.
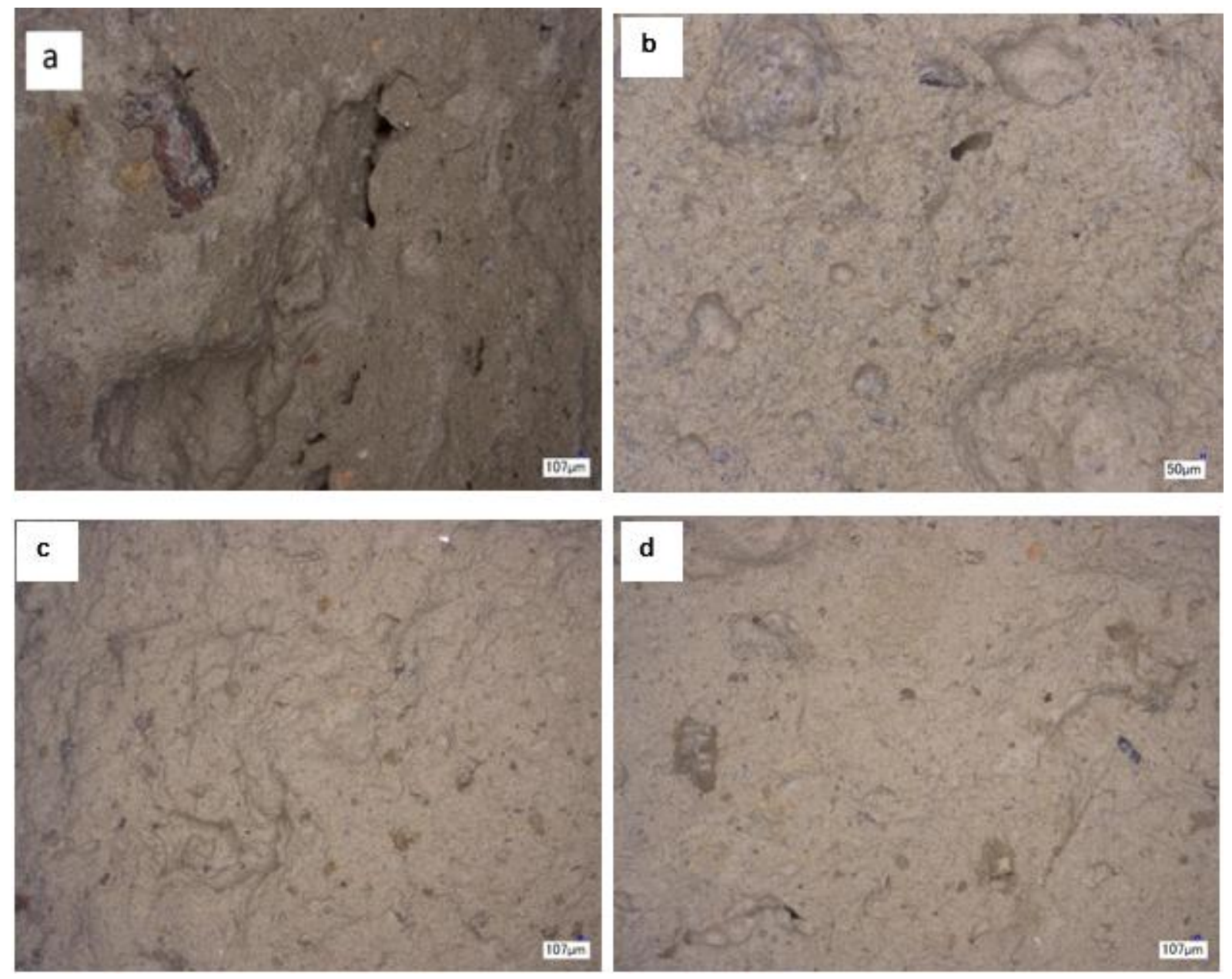

Figure 13: Video optical microscopy images of the adobes

The weight of water absorbed per unit of area versus time and the water absorption coefficient of samples are presented in Figures 14 and 15.

A linear trend is observed in the explored time interval, for the cement-free adobes and those containing 2 wt.\% cement. For higher cement contents, the time interval of the linear behaviour domain is narrower but the slope is steeper. The increase in the rate of water absorption by the adobes, when the cement content is raised, is due to the water demand for the hydration of alite and belite. In other hands, the increase in the rate of 
water absorption by the adobes, when the cement content is raised, is due to the presence of pores into adobes which facilitates water absorption. Moreover, the addition of an increasing proportion of cement modifies the microstructure of the adobe: the reduction in the size of the pores is accompanied by the formation of a solid skeleton rich in cement, which promotes the transport of water by capillarity. The water absorption by these adobes is much greater than those reported by Millogo et al. (2012) [12]. The difference is due to the smaller particle size of the raw material used by these authors: $0.315 \mathrm{~mm}$ against $5 \mathrm{~mm}$ in this study. According to the work reported by Millogo et al. (2008) [11], in basic medium (with $\mathrm{pH}$ higher than 11), crushed fine quartz particles react with portlandite to produce $\mathrm{CSH}$ that contributes to a reduction of the porosity of the adobe, especially the micro-porosity. The results obtained in this study are somewhat different from those reported by Reddy and Gupta (2005a) [8]. However, they used a soil rich in sand which leads to the production of $\mathrm{CSH}$, which helps to reduce the porosity of the sample by linking isolated particles. On the other hand, the difference in results is linked to the procedure used for manufacturing the blocks. Those elaborated for the present study were adobes whereas those elaborated in Reddy and Gupta's work were compressed earth blocks, which are less porous than adobes because of the applied pressure. 


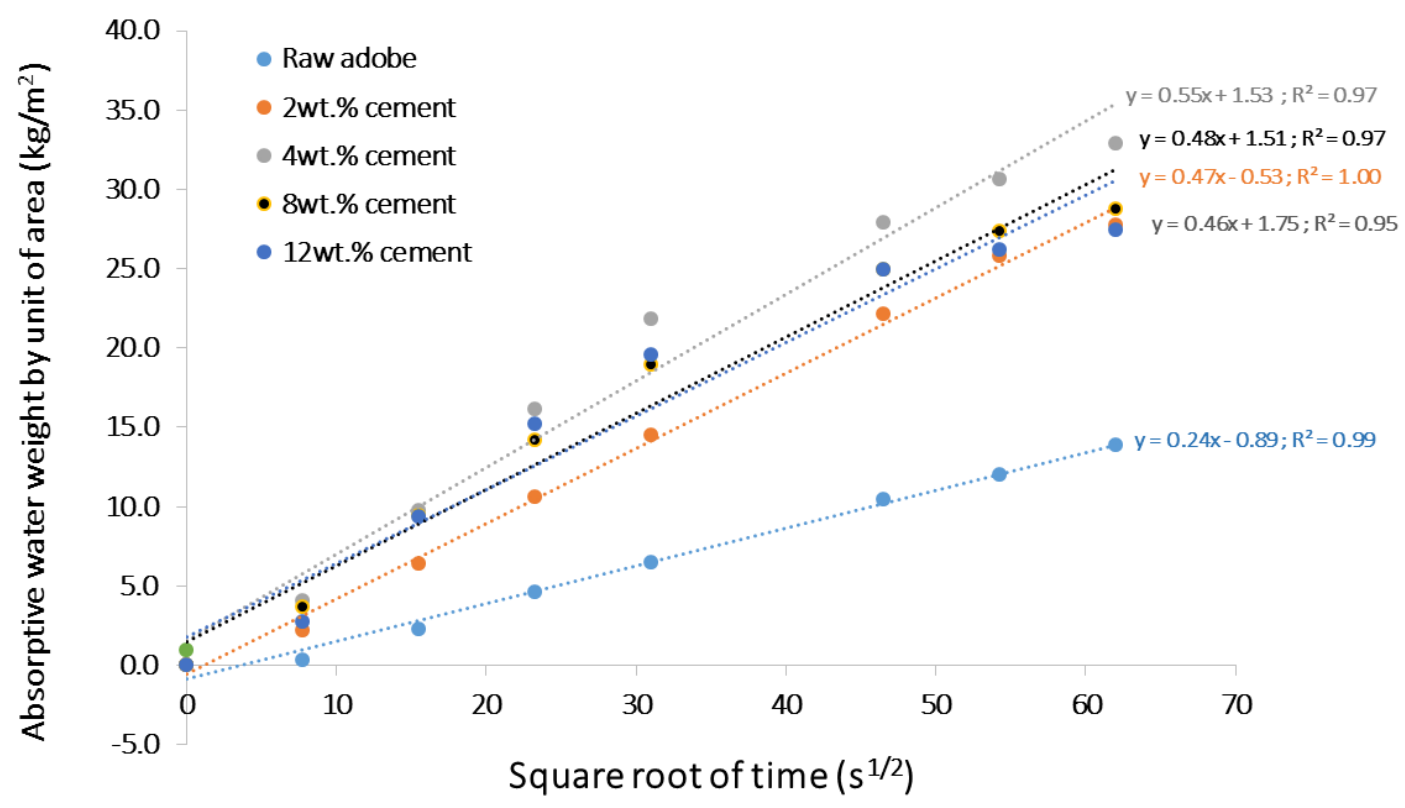

Figure 14: Mass of absorbed water per unit area of adobe versus time

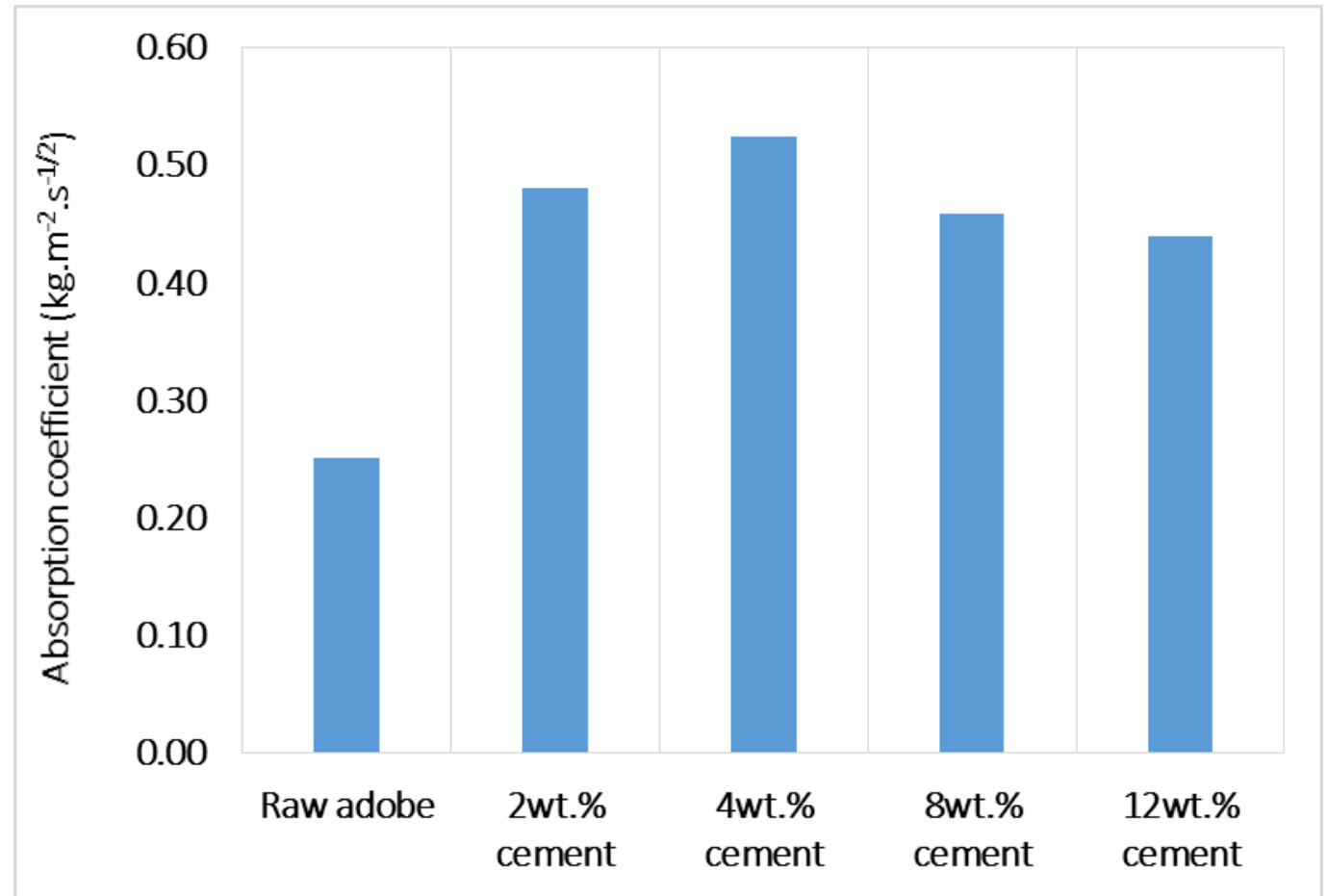

Figure 15: Water absorption coefficients of the adobes 
To appreciate the behaviour of the adobes with respect to rain or a wet climate, a spray test was carried out. The results are presented in Figure 16. As can be observed, the mass loss of adobe decreased when the cement content is increased. The mass loss seems to be stabilized as soon as the cement content reaches a value of $4 \mathrm{wt} . \%$. Raw adobe was much more eroded than those amended with cement (Figure 17). This result was mainly due to the formation of $\mathrm{CSH}$ in the cement-amended adobes, which linked the isolated particles and contributed to a reduction of the total porosity. This result is very important for developing countries because poor people could build their houses with water resistant adobes and thus avoid using plasters made with cement-sand mixture every year, which are expensive because of the price of cement.

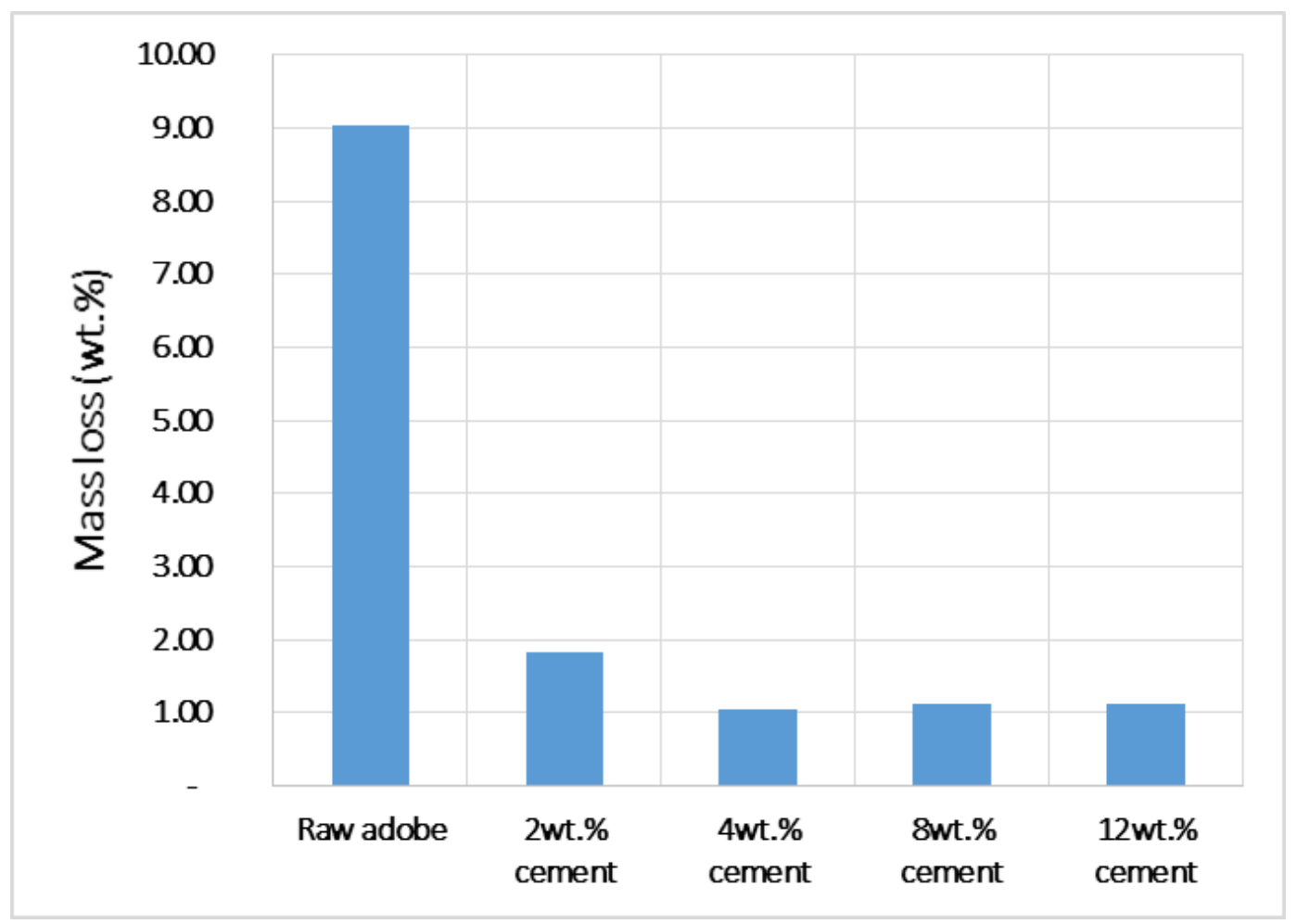

Figure 16: Mass loss of adobes versus cement content (in wt.\%) 


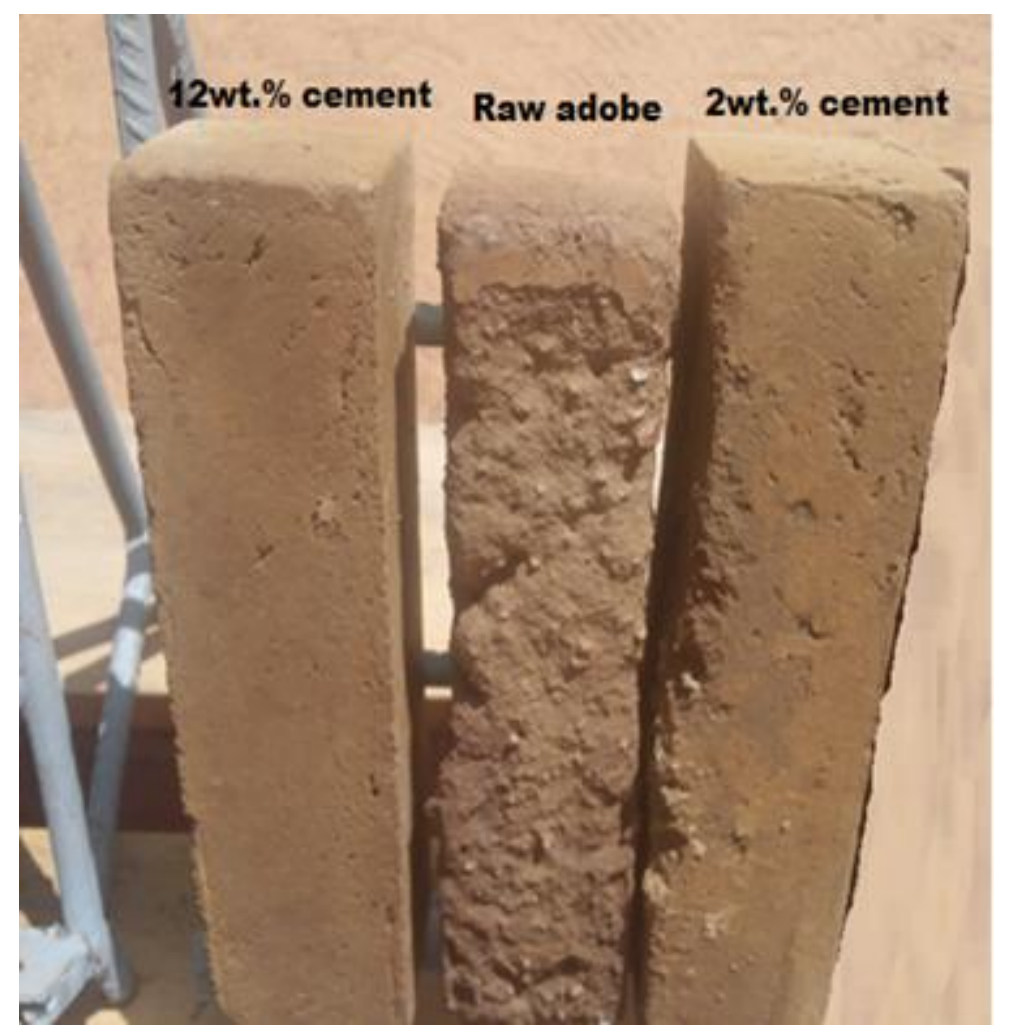

Figure 17: Images of adobes after spray test

The apparent density and closed porosity (calculated using relation 2) of the adobes are presented versus cement content in Figure 18. The absolute densities not presented here, are evaluated on the crushing samples with a pycnometer. The apparent density and closed porosity vary in opposite directions.

The density decreases due to the replacement of soil particles by the less dense cement. The hydration of the cement produces calcium ions, which are attracted to the negatively charged surface of the kaolinite grains. This flocculation mechanism leads to the formation of flakes, which increases the closed porosity of small size pores. The thermal conductivity of the adobes presented in Figure 19 as a function of cement content decreases initially and then increases when the cement content is increased. The observed decrease for low cement contents could be due to a lack of homogeneity of the soil / cement mixture and/or the closed porosity, since the presence of closed pores (filled with air, an insulating 
medium) depresses the thermal conductivity. For cement contents above 4 wt. $\%$, the positive correlation between the cement content and the thermal conductivity is due to the mixture being more homogeneous with important cement additions. Locally, the microstructure of the adobe is modified by the CSH formed (roughly the adobe is transformed into concrete) and that rises the thermal conductivity. The low thermal conductivity of these cement-modified adobes is an important factor for applications in dry climates such as in the Sahel.

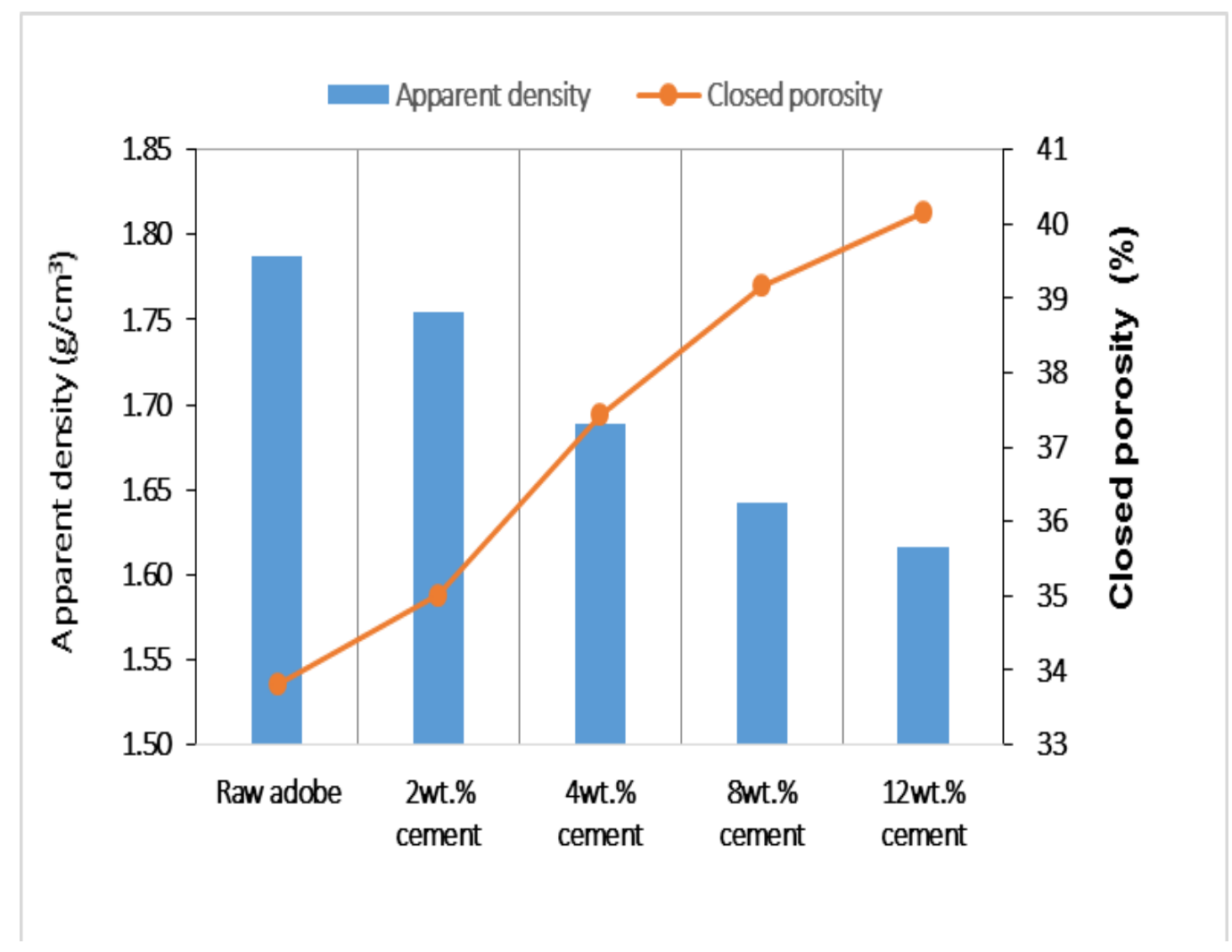

Figure 18: Apparent density and closed porosity of the adobes 


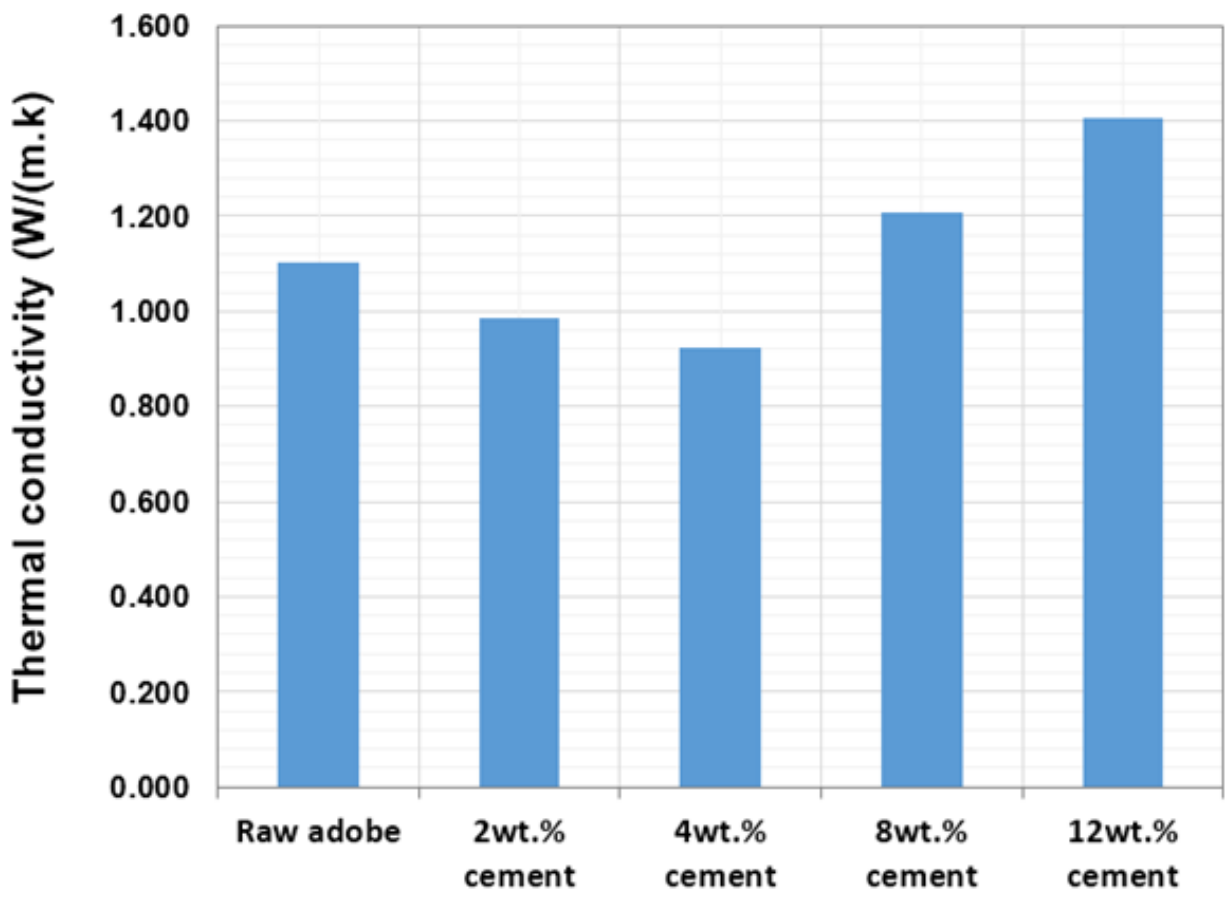

Figure 19: Thermal conductivity of the adobes

The compressive and flexural strengths (Figure 20) increased with cement content. These improvements can mainly be explained by a more homogeneous microstructure (smaller pores and absence of microcracks) when the CSH formed links isolated particles. In the case of earth mortar [34], the strength decreased as the cement content was increased until it reached approximately $6 \mathrm{wt} . \%$. This apparent contradiction may be due to the soil structure used in the present work. The soil was not finely crushed (grain size up to $5 \mathrm{~mm}$ ) and it is known that crushing soils favours the formation of CSH. Reddy and Gupta (2005a) [8] obtained better results than those of the present study because they used a high sand content $(73.3 \mathrm{wt} . \%$ against 42.6 wt.\% in this study). In this case, the cement-sand mixture could behave as concrete. On the other hand, the presence of sand, and especially fine sand, may produce more $\mathrm{CSH}$, which helps to improve the mechanical properties. The disparity between our results and those of Millogo and Morel (2012) [12] is mainly due to the size of the soil grains. In their study, the soil was crushed to a size of $0.315 \mathrm{~mm}$. This process produces more reactive 
fine sand which reacts well with portlandite to produce CSH starting from a pozzolanic reaction. In the present work, the increase in mechanical properties was mainly linked to the formation of CSH (I) during cement hydration and also by pozzolanic reaction involving a lot of fine crushed silica and little kaolinite. All the elaborated cement-stabilized adobes have compressive strength higher than $2 \mathrm{MPa}$ required for most standards about building materials $[35,36,37]$, therefore they are suitable as building materials.

The main results concerning mechanical and thermal properties of cement-stabilized adobes are similar to those reported by Boffoué et al. (2015) and Meukam et al. $(2003$ [20, 38] on earth blocs stabilized by cement. Taking into account of cement price in Burkina Faso which is not accessible for the majority of the population, cement low amount which supplies the required mechanical (taking into account the standards for construction building) and water resistance, low thermal conductivity (near to the value for raw adobes elaborated with soil average $1 \mathrm{~W} /(\mathrm{m} . \mathrm{K})$ at $\left.20^{\circ} \mathrm{C}\right)[15,20]$ must be chosen. For this purpose, cement amount must not exceed $4 \mathrm{wt} . \%$ because it supplies adobes with acceptable mechanical and water resistance, feeble thermal conductivity with a low price of these adobes comparing to conventional materials such as concrete. 


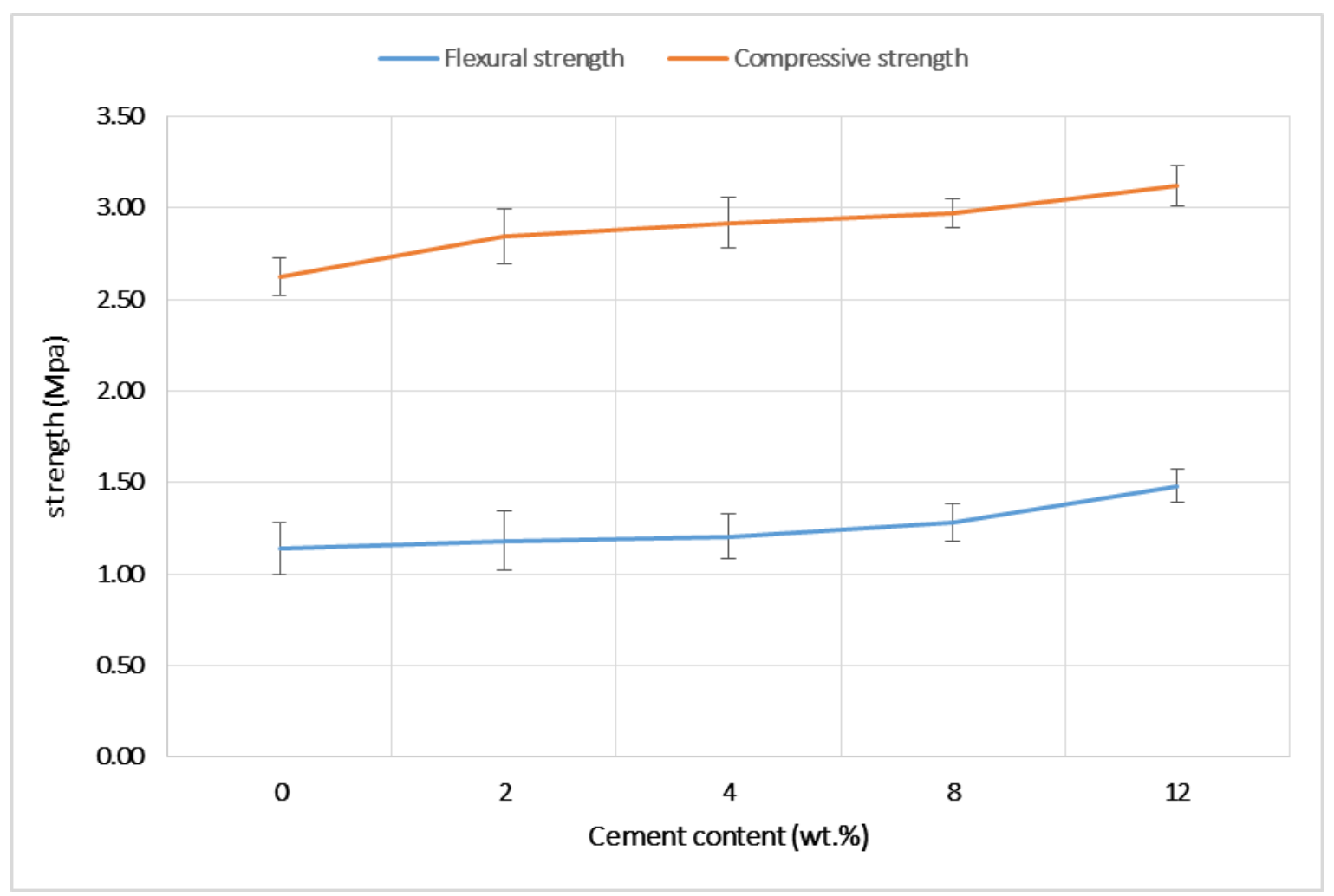

Figure 20: Flexural and Compressive strength of adobes

\section{Conclusions}

The raw clayey material used in this study and composed of quartz (49 wt.\%), kaolinite (28 wt.\%), muscovite (9 wt.\%) and goethite (7 wt.\%) is convenient for manufacture of adobes. The addition of cement to this clayey soil induced the formation of calcite and calcium silicate hydrate CSH (I), ettringite. The CSH came from reactions between the anhydrous components of the cement and water in the hydration stage, while calcite came from reactions between portlandite and carbon dioxide present in the air. $\mathrm{CSH}$ was also provided by pozzolanic reaction, mainly with the reactive crushed quartz and weakly with the kaolinite. The CSH formed led to a homogeneous microstructure with small pores linking the soil particles. The adobes made were shown to be resistant to water erosion and were characterized by good thermal conductivity (especially those with low cement contents). The CSH formed contributed to the improvement of physical and mechanical properties. Cement-stabilized 
adobes with low cement content (2wt.\%) taking into account their compressive strength, water resistance, feeble thermal conductivity (less than raw adobe value), economic aspect are suitable as building materials for the majority of Burkina Faso population.

\section{Acknowledgements}

Younoussa Millogo is grateful to Mrs Kalsibiri Kaboré and Ali Sana of the "Laboratoire National du Bâtiment et des Travaux Publics" for their help in implementing geotechnical and mechanical tests.

\section{References}

[1] H. Kouakou, J.C. Morel, Mechanical performance of nonindustrial building material manufactured with clay as natural binder, Appl. Clay Sci. 44 (2009) 27-34.

[2] J.C. Morel , J.E. Aubert, Y. Millogo, E. Hamard, A. Fabbri, Some observations about the paper "Earth construction: Lessons from the past for future eco-efficient construction" by F. Pacheco-Torgal and S. Jalali, Construc. Build. Mater. 44 (2013) 419-421.

[3] N. Degirmenci, B. Baradan, Chemical resistance of pozzolanic plaster for earthen walls, Construc. Build. Mater. 19(7) (2005) 536-542.

[4] K. Ghavami, R.D.Toledo Filho, N.P. Barbosa, Behaviour of composite soil reinforced with natural fibres, Cem. and Concr. Compos. 21 (1999) 39-48.

[5] B.V.V. Reddy, S. Hubli, Properties of lime stabilised steam-cured blocks for masonry, Mater Struct 35(2002) 293-300.

[6] Q. Piattoni, E. Quagliarini, S. Lenci, Experimental analysis and modelling of the mechanical behaviour of earthen bricks, Construc. Build. Mater. 25 (4) (2011) 20672075. 
[7] S. Yetgin, O. Cavdar, A. Cavdar, The effects of the fiber contents on the mechanic properties of the adobes, Construc. Build. Mater. 22 (3) (2008) 222-227.

[8] B.V.V. Reddy, A. Gupta A, Characteristics of soil-cement blocks highly sandy. Mater. Struct. 38(2005a) 651-658.

[9] B.V.V. Reddy, A. Gupta A, Characteristics of cement-soil mortars, Mater. Struct. 38(2005b) 639-650.

[10] P.J. Walker, Strength, Durability and shrinkage characteristics of cement stabilised soil blocks, Cem. Concr. Comp. 17(1995) 301-310.

[11] Y. Millogo, M. Hajjaji, R. Ouedraogo, Microstructure and physical properties of limeclayey adobe bricks, Construc. Build. Mater. 22 (2) (2008a) 2386-2392.

[12] Y. Millogo, J.C. Morel, Microstructural characterization and mechanical properties of cement stabilised adobes, Mater. Struct .45(2012) 1311-1318.

[13] A. Tironi, C.C. Castellano, V.L. Bonavetti, Kaolinitic calcined clays - Portland cement system: Hydration and properties, Construc. Build. Mater. 64 (2014) 215-221.

[14] H. Khelifi, A. Perrot, T. Lecompte, G. Ausias , Design of clay/cement mixtures for extruded building products, Mater. Struct . 46 (2013):999-1010 DOI 10.1617/s11527012-9949-4.

[15] Y. Millogo, J.C. Morel, J.E. Aubert, K. Ghavami , Experimental analysis of Pressed Adobe Blocks reinforced with Hibiscus cannabinus fibers, Construc. Build. Mater. 52(2014) 71-78. 
[16] Y. Millogo, J.E. Aubert, E. Hamard, J.C. Morel, How properties of kenaf fibers from Burkina Faso contribute to the reinforcement of earth blocks, Materials 8(2015) 23322314.

[17] Y. Millogo, J.E. Aubert, A.D. Séré, A. Fabbri, J.C. Morel, Earth blocks stabilized by cow-dung, Mater Struct 49(2016) 4583-4594.

[18] A. Laborel-Preneron, J.E. Aubert, C. Magniont, A. Bertron, C. Tribout, Plant aggregates and fibers in earth construction materials: a review, Construc. Build. Mater. 111(2016) 719-734.

[19] Y. Millogo, M. Hajjaji, R. Ouedraogo, M. Gomina, Cement-lateritic gravels mixtures: microstructure and strength characteristics, Construc. Build. Mater. 22(2008b) 20782086.

[20] M.O. Boffoué, K.C. Kouadio, C. H. Kouakou, A.A. Assandé, A. Dauscher, B. Lenoir, E. Emeruwa, Influence de la teneur en ciment sur les propriétés thermomécaniques des blocs d'argile comprimée et stabilisée, Afrique SCIENCE 11(2) (2015) 35-43.

[21] J.E. Aubert, A. Fabbri, J.C. Morel, P. Maillard , A soil block with a compressive strength higher than 45 MPa! , Construc. Build. Mater. 47(2013) 366-369.

[22] J.E. Aubert, P. Maillard, J.C. Morel, M. Alrafii, Towards a simple compressive strength test for earth bricks?, Mater. Struct. 49(2016) 1641-1654.

[23] Farmer VC. The infrared spectra of minerals. Mineralogical Society, London , 1974.

[24] J. Madejova, P. Komadel, Baseline studies of the clay minerals society source clays: infrared methods, Clays and Clay Miner. 49 (5) (2001) 410-432. 
[25] M.F. Rojas, J .Cabrera, The effect of temperature on the hydration rate and stability of hydration phases of metakaolin-lime-water systems, Cement Concrete Res. 32 (2002) 133-138.

[26] H.H. Assal, Influence of silica fume on the properties of fired then water cured lime-rich clay bricks, Sil. Ind. 68 (5-6) (2003) 55-60.

[27] C.M.R. Dias, M.A. Cincotto MA, J.H. Savastano, V.M. John, Long-term aging of fibercement corrugated sheets, The effect of carbonation, leaching and acid rain, Cem. and Concr. Compos. 21(2008) 255-265.

[28] D.K. Dutta, D. Bordoloi, C. Prakash, Hydratation of portland cement clinker in the presence of carbonaceous material, Cem. Concr. Res. 25(1995) 1095 -1102.

[29] P. Yu, R.J. Kirkpatrick, B. Poe, P.F. McMillan, X. Cong, Structure of calcium silicate hydrate (C-S-H): near-, mid-, and far-infrared spectroscopy, J. Am. Ceram. Soc. 82(3) (1999) 742-748.

[30] B. Fritz and Y. Tardy, (1973) Etude thermodynamique du système gibbsite, quartz, kaolinite, gaz carbonique, application à la genèse des podzols et des bauxites, Sci. Géol. Bull. 26 (4) (1999) 339-367.

[31] A. Nonat, The structure and stoichiometry of CSH, Cement Concrete Res 34 (2004) 1521-1528.

[32] J. C. Jeffrey, J. T. Jeffrey, H. F. W. Taylor, H.M Jennings, Solubility and Structure of calcium silicate hydrate, Cem. Concr. Res. 34 (2004) 1499-1519.

[33] S. Garrault S, E. Finot, E. Lesniewska, A. Nonat, Study of CSH growth on $\mathrm{C}_{3} \mathrm{~S}$ surface during its early hydration, Mater. Struct., 38(4)(2005) 435-442. 
[34] A. Pkla, A. Mesbah, V. Rigassi J.C. Morel, Comparaison de méthodes d'essais de mesures des caractéristiques mécaniques des mortiers de terre, Mater. Struct. 36(2003) 108-117.

[35] L. Mbumbia, A. Mertens de Wilmars, J. Tirlocq, V. Vandeneede, Influence du processus de fabrication sur les propriétés des briques à base de latérite, Sil. Ind. 65 (9-10) (2000)101-109.

[36] CID-GCB-NMBC-91-1, New Mexico Building code. 1991.

[37] CDI, CRAterre-EAG and ENTPE, Blocs de terre comprimée : procédures d'essais, Technologie $n^{\circ} 16$, CDI, Belgique, mars 2000 .

[38] P. Meukam, A. Noumowe, Y. Jannot, R. Duval, Caractérisation thermophysique et mécanique de briques de terre stabilise en vue de l'isolation thermique de bâtiment, Mater. Struct.36 (2003) 453-460. 